九州大学学術情報リポジトリ

Kyushu University Institutional Repository

\title{
Authenticity, Preservation, and Transnational Space: Comparing Yin Yu Tang and the Linden Centre
}

\section{AZUMA, MARIKO}

Independet Researcher

https://doi.org/10.5109/2794918

出版情報: Journal of Asian Humanities at Kyushu University. 5, pp.29-52, 2020-03. Kyushu University, School of Letters, Graduate School of Humanities, Faculty of Humanities バージョン:

権利関係 : 


\section{Authenticity, Preservation, and Transnational Space: Comparing Yin Yu Tang and the Linden Centre}

MARIKO AZUMA

\section{Introduction}

$\mathbf{T}$ HIS article examines theoretical and practical aspects of authenticity ${ }^{1}$ and the built environment through a comparative case study of two architectural structures: Yin Yu Tang in Salem, MA (USA), and the Linden Centre in Xizhou, Yunnan Province (China). Yin Yu Tang is a two-story, sixteen-bedroom structure that was once home to the Huang merchant family in the Huizhou region of Southeast China. ${ }^{2}$ It was built during the Qing dynasty (1644-1911) and housed generations of the Huang family for almost two hundred years until the mid-198os. ${ }^{3}$ Between 1997 and

I would like to thank Winston Kyan, Lela Graybill, Shundana Yusaf and Windy Zhao for their thoughtful comments and suggestions throughout the various stages of researching and writing this article. The suggestions of various editors and an anonymous reader also greatly helped me improve my argument. Lastly, I would like to thank the University of Utah College of Fine Arts, Department of Art and Art History, for funding essential aspects of my research.

1 On the concept of "authenticity," see Botz-Bornstein, "Hyperreal Monuments of the Mind"; MacCannell, "Staged Authenticity"; and Phillips, Exhibiting Authenticity, p. 197.

2 Peabody Essex Museum, "Yin Yu Tang: A Chinese Home," http:// yinyutang.pem.org/house/base.html. Yin Yu Tang 䔖餘堂 means "Hall of Abundant shelfer"

3 Peabody Essex Museum, "Yin Yu Tang Historical Timeline," http:// yinyutang.pem.org/timeline.html; PEM, "Yin Yu Tang: A Chinese Home."
2003 the vacant house was dismantled, moved in its entirety to the US, reassembled, and finally opened to the public at the Peabody Essex Museum (PEM) under the supervision of the curator of Chinese Art and Culture at the time, Nancy Berliner. ${ }^{4}$

Further southwest from Yin Yu Tang's original location, and located in Yunnan Province, lies the Linden Centre. ${ }^{5}$ The Linden Centre is also a two-story structure that was originally home to a merchant family. However, this building became vacant not long after its construction in 1947. It was converted into a boutique hotel by entrepreneur Brian Linden and opened to the public in 2008. ${ }^{6}$ The Linden Centre offers visitors accommodation that focuses on its distinct setting and context.

4 Berliner, Yin Yu Tang; PEM, "Yin Yu Tang: A Chinese Home"; Rita Reif, "Auctions: Discovering China's Folk Art," The New York Times, 25 January 1987, https://www.nytimes.com/1987/01/25/ arts/auctions-discovering-china-s-folk-art.html.

5 The Linden Centre, "Welcome to the Linden Centre," http:// www.linden-centre.com/. The Linden Centre is also known as Xi Lin Yuan 喜林苑 in Mandarin, which translates to "Joyous Linden Park."

6 Ibid. See also "Our Team," http://www.linden-centre.com/ team/; "Linden Gallery," https://www.lindensgallery.com/. Brian Linden and his wife Jeanee oversee the Linden Centre in Yunnan and operated until 2019 the Linden Gallery in Door County, Wisconsin, which featured antiques collected on their journeys through Asia. 


\section{- Method and Theory}

This article argues that despite similarities in architectural origins, materials, symbolical significance, and layout, Yin Yu Tang and the Linden Centre display distinctly different interpretations of preservation and authenticity, which has led to their contemporary identities. Yin Yu Tang has been turned into one of the highlights of the PEM and is undoubtedly one of the most prized possessions of the collection, symbolizing the wider international relationships that the museum has to offer. In contrast, the Linden Centre provides a temporary safe haven for tourists traveling far from their homes and offers them a minority cultural experience. Both structures are no longer the permanent, private, and enclosed homes of generational families. Instead, they have become temporary, public, and porous spaces that are occupied, looked at, and observed by tourists.

As transformed artworks and architectural subjects, Yin Yu Tang and the Linden Centre have both conceptually and physically taken on new functions and identities. One became part of a museum collection, the other a "living museum." I believe that sustainable, long-term preservation must understand and accommodate the conceptual, personal, and unattainable idea of authenticity - that is, the meaning of authenticity as unstable, expansive, and adaptive to its circumstances. Moreover, I argue that when appreciating authenticity obtained through protection or commodification like the Linden Centre and Yin Yu Tang one has to be always aware of the mechanisms of display that are inevitably at work. For example, despite the immersive "insider" experience represented by these two houses, the fantasy of an insider experience depends on the status of the visitor as a perpetual outsider. This is a result of working within the framework of display, which can easily be taken as an act of preservation that directly produces authenticity.

In both cases, the buildings have been altered simply by their re-contextualized and reinterpreted environments that prevent the possibility of an authentic, original experience ever being achieved. More importantly, long-term preservation of architecture enables the future development of the buildings through the creation of a new tradition. This is a distinguishing

7 Linden Centre, "Our Vision," http://www.linden-centre.com/ about/. characteristic of architectural preservation because it involves space, and space must address functions that define the past, the present, and the future of a building. This intersection of space, time, and display is where the complex possibilities and challenges of preservation become apparent.

I argue that Yin Yu Tang and the Linden Centre are examples of vernacular architecture that use re-contextualization to cultivate a new "authenticity" found within the framework of display. Although many of the intentions and efforts of preservation are sincere, a longer-lasting approach should aim instead to respectfully reuse the past to construct a future authenticity.

The strongest tie between Yin Yu Tang and the Linden Centre is their negotiation of preservation and authenticity. They both represent singular examples for the future preservation of vernacular architecture and offer a unique opportunity to examine methods of architectural preservation as well as the underlying limitations, assumptions, and tendencies within preservation.

Discussions with Brian Linden and Nancy Berliner revealed their differing approaches. Berliner approaches China primarily through academic endeavors while Linden has engaged in China through various business and education ventures within the hospitality sector. They are both Western educators of Chinese culture as well as beholders of disparate Orientalist perceptions and an "aesthetic eye" in relation to Chinese art, architecture, and rural culture. ${ }^{8}$ This article prioritizes the study of the architecture as experiential artworks over the study of the individuals involved in their projection.

Based on these primary encounters and various source materials, I argue that meaningful preservation must challenge traditional approaches to authenticity through the following three lenses. The first lens, entitled "The Past," considers the transformation from space to place shared by Yin Yu Tang and the Linden Centre. I consider definitions of preservation and authenticity and how they have spurred the historical changes and contemporary identity of each site. The second lens, "The Present," explores the impact of transnational and transcultural identity on the preservation and display of Yin Yu Tang and the Linden Centre, and discusses how each site communicates its past through

8 Nochlin, "The Imaginary Orient." 
physical, sensory, and visual mechanisms. The last lens, "The Future," considers the process of authentication as an ongoing and intentional construction of tradition at each site, and speculates about the visual and material future of placemaking at each site as related to issues of architectural heritage and preservation.

\section{The Past}

\section{- Preservation and Authenticity}

At the core of this analysis is the delicate intersection of authenticity and preservation. "Authenticity" refers to a sense of originality, accuracy, or truthfulness. The term has developed different uses in the fields of urban conservation and art history, leading to a vast amount of discussion and variation in the definition, ranging from scientific to humanistic approaches. ${ }^{9}$ The "Principles for the Conservation of Heritage Sites in China," also known as the China Principles, were adopted in 2000 and issued by ICOMOS (International Council on Monuments and Sites) China in 2002. ${ }^{10}$ This document defines a site as authentic if its preservation oc-

9 Zancheti, Lira, and Piccolo, in "Judging the Authenticity of the City," p. 163, base their discussion on UNESCO guidelines that state that authenticity in urban conservation is defined as a "measure of the degree with which the attributes of cultural heritage, form and design, materials and substance, use and function, traditions and techniques, location and setting, spirit and feeling, and other factors credibly bear witness to its significance." Yujie Zhu states that the rise of postmodernism, poststructuralism, and constructivism has led authenticity to become a projection of one's beliefs, context, ideology, and even imagination; see Zhu, "Cultural Effects of Authenticity," p. 596. Existential authenticity is discussed as a characteristic that originates from identity, social relationships, and selfrealization; see Rickly-Boyd, "Existential Authenticity: Place Matters," and Jiang et al., "Authenticity." For a dictionary definition of "authentic" see Oxford Living Dictionaries, https:// en.oxforddictionaries.com/definition/authentic.

10 Weiler, "Aspects of Architectural Authenticity in Chinese Heritage Theme Parks," p. 222. The China Principles are based on the Venice Charter of 1964 that states that monuments should be conserved not only as works of art but as historical evidence; see ICOMOS Venice Charter. J. Paul Getty Trust, "Cultural Heritage Policy Documents," The Getty Conservation Institute, http://www.getty.edu/conservation/publications_resources/ research resources/charters/charter12.html. China joined the Convention Concerning the Protection of the World Cultural and Natural Heritage in 1985, more than a decade after its adoption by UNESCO in 1972. The China Principles is a significant document based on the Law of the People's Republic as well as the Venice Charter from 1964, indicating their awareness of both international practice and the nation's legal requirements and curs in accordance with international practices and if it possesses originality, or zhenshi (xing) 真實 (性) - a character compound that combines meanings of "true" and "fact/reality."

Another school of thought expressed in the 1995 definition of authenticity by Jukka Jokilehto and Paul Philippot for ICCROM (International Centre for the Study of the Preservation and Restoration of Cultural Property) states it as "a measure of the truthfulness of the internal unity of the creative process and the physical realization of the work, and the effects of its passage through historical time," which takes authenticity as inclusive of the changes that come with time. ${ }^{12}$ At the International Congress, "Preserving Transcultural Heritage" in Lisbon (Portugal) in 2017, Jokilehto defined authenticity more specifically and conceptually as something dynamic rather than static: "The creative process that forms significance, where integrity contributes to this significance and specificity of cultural expression." ${ }^{13} \mathrm{He}$ highlights the fact that authenticity is not just a value judgment, but is dependent on particular contexts of who, where, and why authenticity is being discussed. For Jokilehto authenticity is therefore a value that is not only inherently found in a building, but is rather created, nurtured, and acted upon. ${ }^{14}$

In this article, I refer to the definition of authenticity that fuses identifiers of context, spirit of place, and the passage of time that are mentioned above. ${ }^{15}$ Rather than attempting to define what is authentic in Yin Yu Tang and the Linden Centre, I will discuss how authenticity is approached by the respective sites and stakeholders in a dynamic, shifting way.

needs. Zhu, "Authenticity and Heritage Conservation in China," p. 187.

11 Weiler, "Aspects of Architectural Authenticity," p. 224.

12 See Jokilehto, "Paul Philippot (1925-2016)," ICCROM, last modified January 25, 2016, https://www.iccrom.org/news/ paulphilippot-1925-2016; Phillips, Exhibiting Authenticity, p. 128.

13 Jokilehto, "Keynote Speaker Lecture: Questions of Authenticity Concerning Different Cultures and Preservation"; see also Jokilehto, A History of Architectural Conservation.

14 Weiler, "Aspects of Architectural Authenticity," p. 224; see also Zhu, "Performing Heritage: Rethinking Authenticity in Tourism" p. 1496. Within the study of tourism, authenticity has been discussed at length using conceptual approaches such as objective, constructive, and existential authenticity. My research incorporates some of the various facets of authenticity, but ultimately focuses on how it is approached through display.

15 Key authors include Jukka Jokilehto, Katharina Weiler, and Yujie Zhu among others. Key terms are discussed in the ICOMOS Venice Charter 1964 and by the UNESCO World Heritage Centre. 
Preservation, too, is a loaded term. It cannot be limited to the restoration or the reconstruction of a structure through a unified style unique to its original condition. ${ }^{16}$ I will be referring to the broad definition of preservation that is used interchangeably with conservation as something that safeguards and protects architectural heritage. ${ }^{17}$ As quoted by Philippot, preservation expresses the "modern way of maintaining living contact with cultural works of the past." ${ }^{18}$ I believe the key term here is "living," which places the future of the preserved object with the viewers and/or users of the object rather than completely stabilizing the object in a time capsule. ${ }^{19}$ Jokilehto furthermore connects preservation to authenticity, in that, "conservation is not only keeping the material, but also recognizing this spirit, this 'non-physical' essence and authenticity of the heritage, and its relation with the society," highlighting the fact that preservation must consider both tangible and intangible characteristics and practices attached to a building's history. ${ }^{20}$ Within preservation, I am particularly interested in the process that combines the object's tangible and intangible history, meaning, and material with subsequent actions of protection that ensure the longevity of the structure.

The relationship between authenticity and preservation is a complicated one. Preservation is what one would expect to be a prerequisite for authenticity, creat-

16 For more on the history of restoration and reconstruction, particularly Alois Riegl's role in the discourse, see Lamprakos, "Riegl's 'Modern Cult of Monuments' and the Problem of Value," pp. 421-22; for further discussion on cultural differences in heritage discourse, see Zhu, "Cultural Effects of Authenticity," p. 597. It is important to note that the definitions of both authenticity and preservation are extremely variable in their interpretations, resulting in different understandings between Western and Chinese ideology. The differences stem from not only historical narratives but also the different attitudes towards achieving the "enduring moment" and meaning of place.

17 ICOMOS, The Nara Document on Authenticity (1994). Appendix 2 defines conservation as "All the efforts designed to understand cultural heritage, know its history and meaning, ensure its material safeguard and, as required, its presentation, restoration and enhancement." It furthermore notes that cultural heritage includes monuments, groups of buildings and sites of cultura value (defined in Article 4 of the World Heritage Convention); UNESCO World Heritage Committee, "Glossary of World Heritage Terms," UNESCO Convention Concerning the Protection of the World Cultural and Natural Heritage, 1996, http://whc. unesco.org/archive/gloss96.htm.

18 Domicelj, "Authentic? Nara Revisited...," p. 152.

19 For more on time capsule settings, see Phillips, Exhibiting Authenticity, p. 129.

20 Domicelj, "Authentic? Nara Revisited...," p. 152. ing the most suitable situation for the genuine form of a structure to be experienced and savored by future generations. However, in any scenario where both terms are used, careful decision-making and oftentimes contradicting effects and results are involved. This raises questions of what exactly is intended with the preservation of vernacular architecture, and how authenticity ought to be placed within the discussion in a manner that does not undermine its meaning.

Alois Riegl's classic essay presents this problematic relationship between preservation and authenticity by arguing for the expansion of values that guide preservation. ${ }^{21}$ Riegl insisted on understanding sites and artworks not through standards prescribed by established canons progressing toward artistic ideals, but through values that are interchanging and based on subjective perceptions and sensibilities of the viewer, thus going so far as to claim art history as the "history of perception." 22

I believe that these subjective approaches are indicative of the need to understand architectural value and authenticity as a whole, and how artworks encapsulate not only materials and cultural history, but the effects, emotions, and personal connections that the object evokes within the contemporary viewer. This approach also sheds light on how a site's value, qualities, and authenticity for subsequent preservation means working within distinct segments of time: the past, present, and the future. Objects were made in the past for a specific purpose and context that are always different from those in the present or the future. ${ }^{23}$ This means that there are definitive and inevitable differences and changes in the understandings of authenticity and preservation that must be taken into consideration. ${ }^{24}$ Yin Yu Tang and the Linden Centre must be viewed through a lens of authenticity and preservation that largely considers the site and location, as well as the malleable definitions that consider the viewer. Therefore, it is vital to understand a structure by asking the following questions: "What is being preserved?" and "Whose tradition, cul-

\footnotetext{
21 Riegl, "The Modern Cult of Monuments: Its Character and Origin."

22 Lamprakos, "Riegl's 'Modern Cult of Monuments' and the Problem of Value," p. 427. By understanding art history as a "history of perception," Riegl focused on the dynamic relationship between the viewer, subject, and object (p. 422). 23 Summers, Real Spaces, p. 56.

24 Lamprakos, "Riegl's 'Modern Cult of Monuments' and the Problem of Value," p. 429.
} 


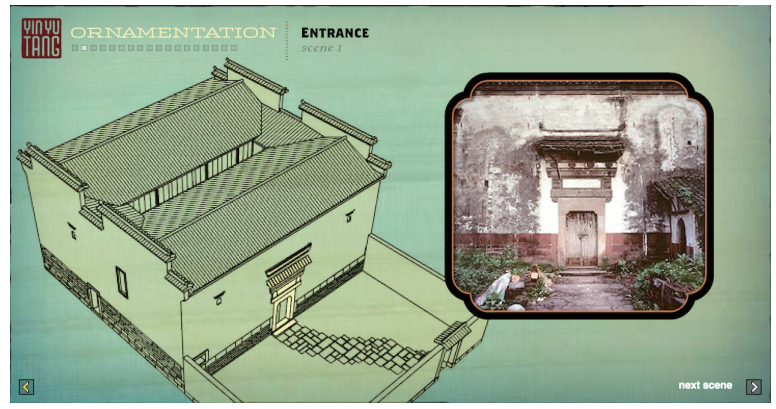

Figure 1. Axonometric plan of Yin Yu Tang (left) and photograph of main entrance of Yin Yu Tang in its original location (right). Second Story, 2002, "Ornamentation: Scene 1" of interactive website, Yin Yu Tang: A Chinese Home. Photoraph by Cheng Shouqin. In the public domain.

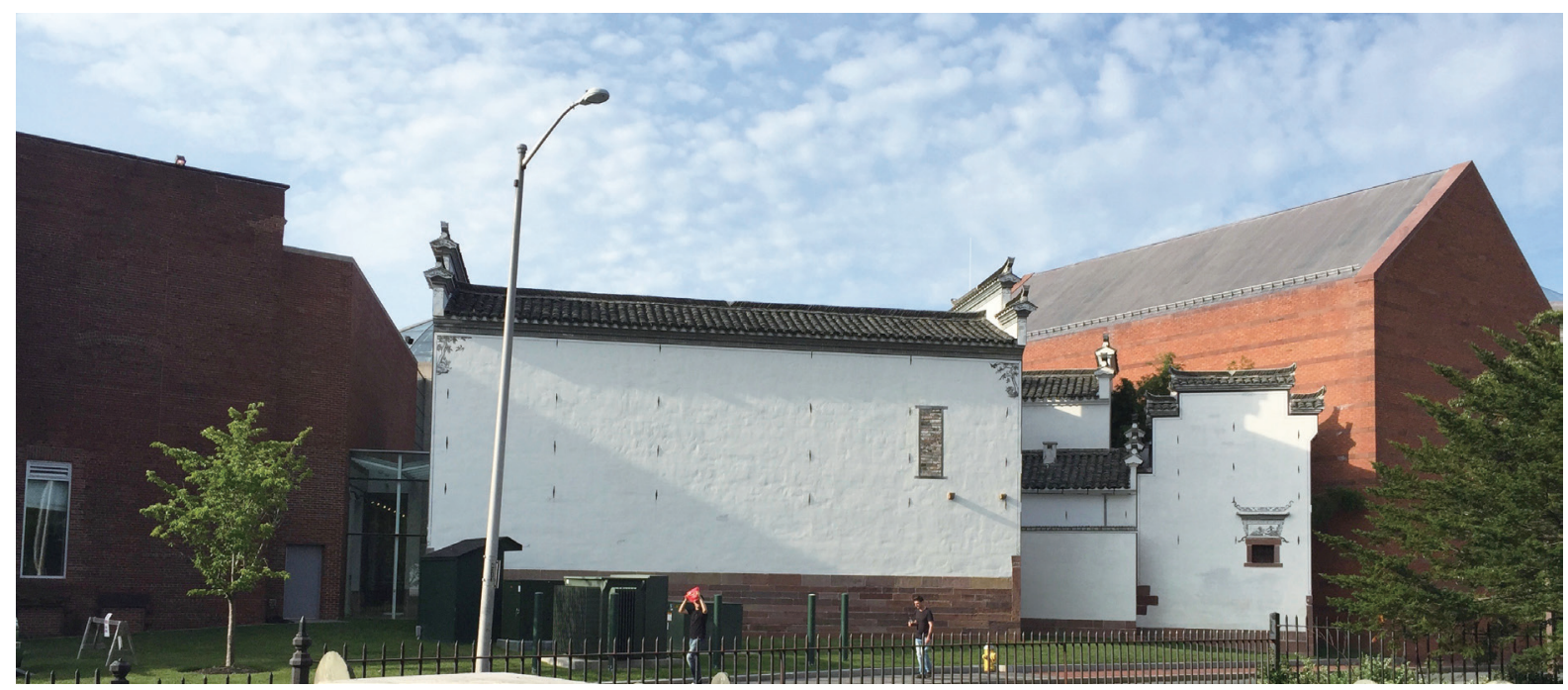

Figure 2. Exterior of Yin Yu Tang at the PEM. The back side is visible from the outside of the PEM but the structure can only be entered from inside the PEM. Photograph by author.

ture, or history is being preserved?"25 These contextual questions reveal the increasingly broad, fluid, and negotiable approaches to authenticity and preservation.

\section{- Yin Yu Tang and the Linden Centre in the Contemporary Context}

Yin Yu Tang represents the fortress-like architecture common to the Huizhou region of Southeast China (figures 1-2). Once the visitor enters the main exterior courtyard of the house, they are faced with a white plastered wall, embedded with two tiny windows on either

25 Low, "Cultural Conservation of Place," p. 71 corner and a main entrance with brick and stone decorations placed above it. This exterior space is rather constricting and creates a sense of visual and physical separation and protection between those inside and those outside. One step past the wall and into the interior of the house presents a highly contrasting sense of warmth and detail created through an array of textures and colors. Aging stone floors, wooden lattice windows, floral European wallpaper, and dark wooden ceilings surround a small courtyard or sky well in the center of the house. This courtyard containing two fishponds provides light and air to the sixteen bedrooms of the two-story house, each of which is occupied by traces of the previous inhabitants' family history. Features of a more recent past are also visible through these traces, since the house was inhabited until the 1980s. Posters 


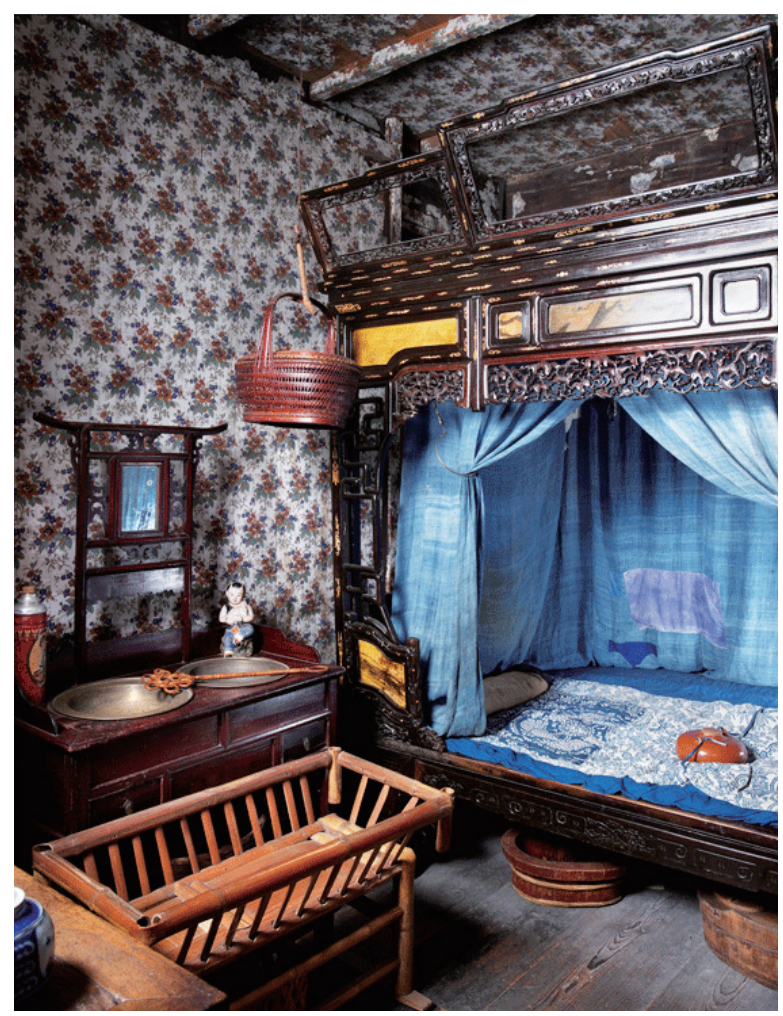

Figure 3. Bedroom in Yin Yu Tang decorated with imported European wallpaper in 1926 for an eldest son's marriage. PEM. Photograph by Dennis Helmar. Permission of Peabody Essex Museum.

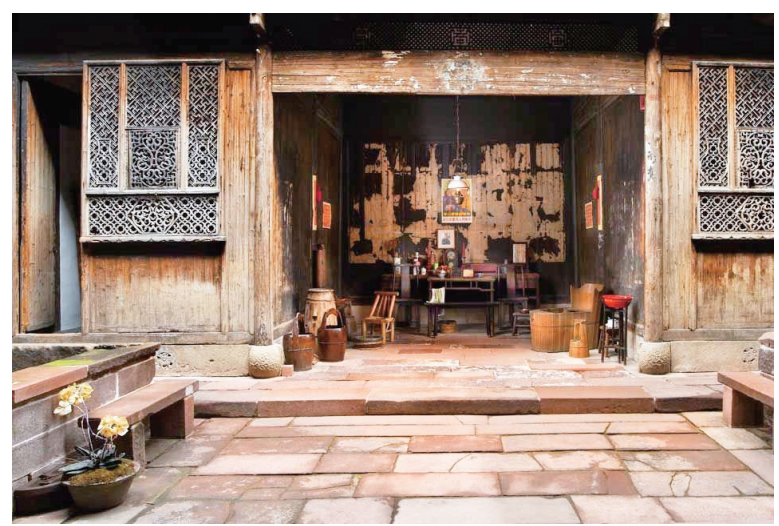

Figure 5. Figure 6. Reception hall, Yin Yu Tang, PEM. Photograph by Dennis Helmar. Permission of Peabody Essex Museum.

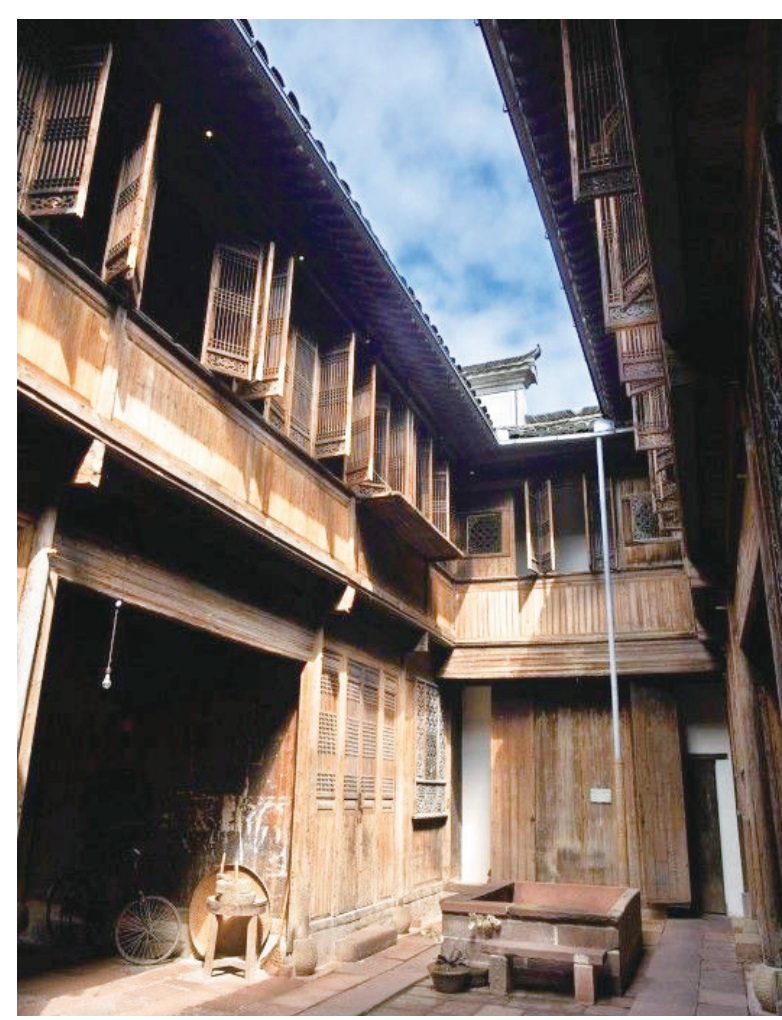

Figure 4. Courtyard or "sky well" of Yin Yu Tang. PEM. Photograph by Dennis Helmar. Permission of Peabody Essex Museum.

of Chairman Mao and a government-installed loudspeaker from the Cultural Revolution (1966-1976) remain fixed to the walls, and these are juxtaposed with older and traditional aesthetics, such as stone column bases with floral designs and lattice windows with symbolic imagery of peace and harmony (figures $3-5){ }^{26}$

This visually rich experience is made possible through a chain of events that brought Yin Yu Tang, which translates as Hall of Abundant Shelter, from China to its new foreign context. It was originally built to express the hopes of one male member of the Huang family who lived in the village of Huang Cun in the Huizhou region in present-day Anhui Province in Southeast China. ${ }^{27}$ This region is known for its majestic landscape surrounded by the Huangshan Mountains, whose peaks loom over the rural village.

26 PEM, Yin Yu Tang House Audio Tour. 27 Berliner, Yin Yu Tang, p. 113 
Although the exact date is unknown, a son belonging to the twenty-eighth or twenty-ninth generation built the home around 1800 with the desire that it would one day shelter future descendants. ${ }^{28}$ As he had hoped, the Huang family continued to grow as a wealthy merchant family and occupied the home for nearly two hundred years. However, in the mid-1980s, the growing desire and need to move to towns and larger cities ultimately led to the family's decision to put the home up for sale. Shortly after, in 1996, Nancy Berliner came upon the house amid transition. It was agreed that it would be moved to the PEM as a form of cultural exchange to protect and showcase the region's architecture. The entire house was carefully taken apart, shipped across the world, and rebuilt in its original configuration on the museum grounds, which is also home to twenty-three other historic homes. ${ }^{29}$ In 2003 , Yin Yu Tang was opened to the public in the courtyard of the PEM alongside an exhibition room that displays the history of the Huang family, the culture of Anhui Province, and information on contemporary life in the region that is known today as Huangshan municipality.

Yin Yu Tang's unique re-contextualization and preservation is comparable to the "period room" concept in many museums, featuring experiences that are meant to temporarily immerse the visitor in spaces belonging to another time period or culture. Period rooms often take a picture-box format by creating a physical and conceptual frame around a space. A set viewing point is allocated from which the visitor can peer into the recreated, three-walled "treasure casket" that is meant to carry the illusion of the space being extracted from a long-gone era or a vastly different foreign country. ${ }^{30}$ This means that there are opportunities for the viewer to freely imagine and create connections between the visible objects and images present in the space with the people, relationships, and interactions that would have been present in the space. However, "period rooms" also inhibit certain interpretations by possibly displaying generalizations and preconceptions. ${ }^{31}$

Against this background, Yin Yu Tang is unique

28 PEM "Yin Yu Tang Historical Timeline."

29 PEM, "Yin Yu Tang: A Chinese Home."

30 Harris, Moving Rooms, p. 6; Minneapolis Institute of Art, "What Are Period Rooms, Really?," https://new.artsmia.org/ stories/what-are-period-rooms-really/. Examples of Chinese period rooms include the Astor Court and the adjoining Ming Reception Room at the Metropolitan Museum of Art, as well as the Wu Family Reception Hall and Scholar's Library and Study at the Minneapolis Institute of Art; for a brief discussion see Azuma, "Yin Yu Tang and the Effects of Re-contextualization on Vernacular Architecture."

31 For further discussion on the effects of this dynamic, see Phillips, Exhibiting Authenticity, p. 200. in that it is not just a single room but an entire house that has actually been extracted and transported from its original location, creating a much more raw and immersive experience for the visitor who is able to walk into the house and up to the second floor. There are no museum labels, and so visitors learn about the house and its history through personal audio guides. However, Yin Yu Tang's presentation continues to be interpreted in the museum context, which includes stakeholders such as curators and visitors. In an earlier study I concluded that Yin Yu Tang is not representative of authentic local architecture but presents a valuable and communicative object in a foreign context that acts as a microcosm from the past, aiding in the ongoing dialogue between authenticity and preservation. ${ }^{32}$ The preservation of this work of traditional Chinese architecture in New England becomes even more distinct and complicated when compared to the preservation and maintenance of Chinese minority architecture within China, represented by the Linden Centre.

The Linden Centre, originally known as "Yang's compound" after the owner's family, is a residential complex built in 1947 in the village of Xizhou, Yunnan Province. Yunnan is a melting pot of rich culture and history because of its privileged location along trade routes between Southeast Asia, Central China, and Tibet. ${ }^{33}$ It is also home to most of the fifty-six ethnic minorities in China. ${ }^{34}$ Xizhou itself is known as the "Cradle of Bai Civilization." ${ }_{35}$ The Bai are an ethnic minority with a 1,300-year history and are renowned for their wealth through business and cultural exchange. These cultural and geographic aspects have affected the architecture of the region, which is apparent throughout Xizhou, including the prominently established Linden Centre.

Unlike Yin Yu Tang's fortified, white walls, the Linden Centre has a soft, earth-toned exterior wall that spreads across an open rice field, creating an impressive and highly visible approach from afar (figure 6). The visitor enters the property through a narrow pathway that leads to an archway exquisitely covered with detailed woodwork, bracketing, and colorful imagery of

\footnotetext{
32 Azuma, "Yin Yu Tang and the Effects of Re-contextualization on Vernacular Architecture."

33 BBC, "Asia's Ancient Tea Horse Road," BBC Travel, http://www. bbc.com/travel/story/20120830-asias-ancient-tea-horse-road.

$34 \mathrm{Fu}$ and Steinhardt, Chinese Architecture, p. 5.

35 Berg, "Life with the Lindens," p. 49.
} 
wealth and infinity in the typical Bai style. ${ }^{36}$ The courtyard beyond visually complements the arch with similar detailed woodwork along the second-floor balcony, dark stone floors, and delicate carvings and paintings of animals, plants, and geometric figures placed throughout the structure. The Linden Centre is much larger than Yin Yu Tang, partially due to renovations, with three courtyards that encompass sixteen rooms along with other spaces utilized as a dining room, meeting room, children's room, office, library, and kitchen. ${ }^{37}$ This organized layout adheres to its main function and identity as a boutique hotel (figures 7-11).

The original owner of the Linden Centre was a wealthy local entrepreneur, Yang Pin Xiang 杨品 相 (1900-1975)..$^{38}$ Not long after its construction, and throughout the Communist revolution and the founding of the People's Republic of China in 1949, Yang's compound was converted into a number of different things, including a military barracks, a hospital, and a kindergarten. Fortunately, it remained largely intact during these changes and in 2001, Yang's compound was designated a Nationally Protected Heritage Site. ${ }^{39}$

In 2006, Brian Linden came to Xizhou and started negotiating with the local government to secure the rights to Yang's compound. ${ }^{40}$ Once permission was given, Linden and his family spent another year renovating the building and converting it into a hotel. In October 2009, it was opened to the public as "the only

36 Kitty Huang and Irene Wu, "The Linden Centre: A Tour Through Yang Pin Xiang's Home," trans. May Baverman, in The Linden Centre Blog, entry posted 30 May 2018, https://thelindencentre. blog/2018/05/30/the-linden-centre-yang-ping-xiangs-home/; Matt Xu, "The Linden Centre Tour," lecture given at the Linden Centre, Xizhou, 19 May 2017.

37 Huang and Wu, "The Linden Centre: A Tour Through Yang Pin Xiang's Home."

38 lbid. Yang Pin Xiang operated a company that traded gold, foreign currency, and cotton yarn in places such as Hong Kong, Kunming, and Xiaguan, and was also actively involved in promoting his hometown through a magazine called New Xizhou during his time in Shanghai on business.

$39 \mathrm{lbid}$. This designation may also be indicative of an increasing awareness of the need to preserve not only in a global but a specifically Chinese context. Compare Weiler, "Aspects of Architectural Authenticity," p. 222.

40 James Fallows, "Village Dreamers," The Atlantic, last modified October 2009, https://www.theatlantic.com/magazine/ archive/2009/10/village-dreamers/307657/. Through the 1990s, Linden and his wife also built their Asian arts antique business in Door County, Wisconsin, which operated from 1995 to 2019. Named the Linden Gallery, this space housed objects selected by the Lindens on their trips throughout Asia. See https://www. lindensgallery.com.

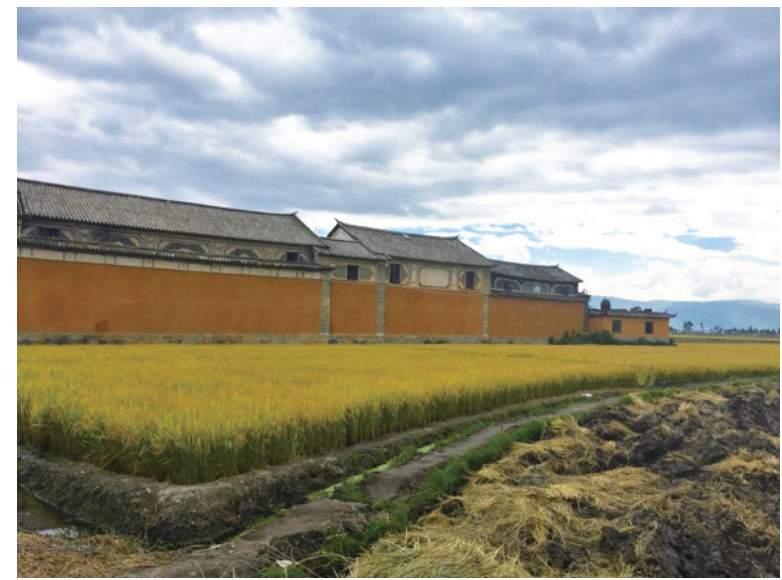

Figure 6. Exterior of the Linden Centre in Xizhou. Photograph by author.

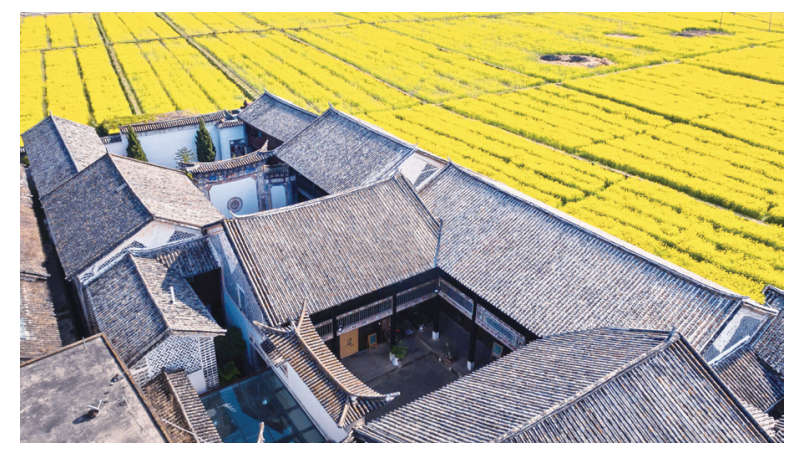

Figure 7. Layout of the Linden Centre with three courtyards. The main entrance is to the north, and the back end of the structure faces southeast. "The Linden Centre: A Tour through Yang Pin Xiang's Home," the Linden Centre blog. Photograph by Xiao Long Ge. Permission of the Linden Centre.

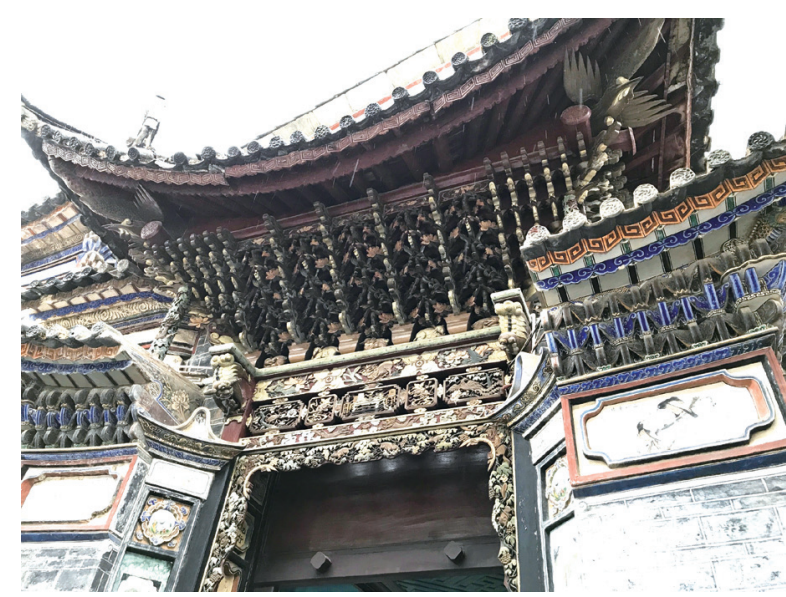

Figure 8. The Linden Centre's archway of the first courtyard. Photograph by author. Permission of the Linden Centre. 


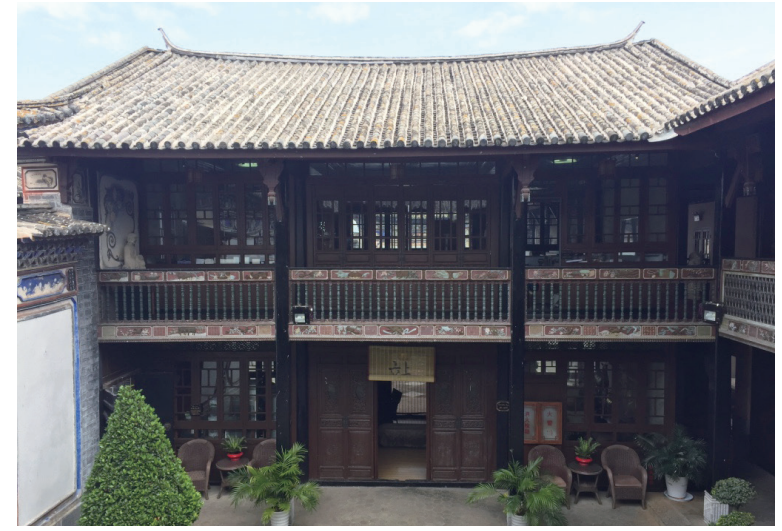

Figure 9. The Linden Centre's first courtyard facing the bar/café on the first floor and the office space on the second floor. Photograph by author. Permission of the Linden Centre.

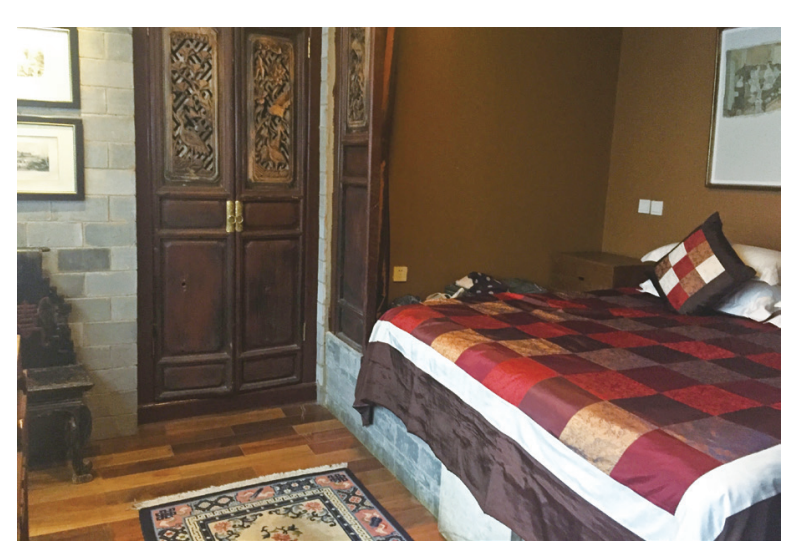

Figure 10. Interior of a guest room at the Linden Centre. Besides a $T V$, if inludes all amenities one would expect from a western hotel. Photograph by author. Permission of the Linden Centre. Permission of the Linden Centre.

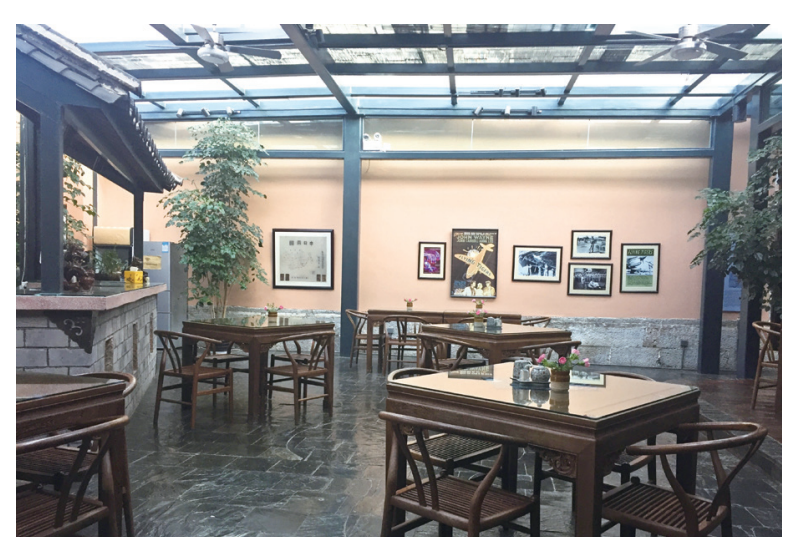

Figure 11. The dining area of the Linden Centre. Photograph by author. Permission of the Linden Centre. nationally protected heritage site that offers guests an intimate look into the grandeur of China's past and ever-changing present." ${ }^{11}$ Today, the Linden Centre offers a variety of themed activities, tours, and education programs to promote the local culture, all within familiar and comfortable accommodation and amenities for the large number of Westerners who stay at the facility. The Linden Centre and its approach to preservation challenges other forms of preservation by taking in new traditions and meanings and reinterpreting them for visitors. For the Linden Centre, preservation can partially be seen as an act that uses the physical remnants and conceptual memories of past identity to create and stage Bai culture, prioritizing the new identity of the building over the old.

\section{- The Transformation from Space to Place}

Berliner has stated that architecture is an extremely relatable way to understand a culture because it provides a sense of social interaction within a real space..$^{42}$ This phrase "real space" made me ponder what indicates a space as "real" physically and conceptually. Despite the different treatment that Yin Yu Tang and the Linden Centre have gone through, both have experienced change in a way that has transformed the respective identity of the building, its history, and its culture to an elevated status that viewers experience today. Fundamental for a full grasp of Yin Yu Tang and the Linden Centre as not only transformed artworks, but architectural forms of art that originally housed people, is the idea of space and place, a concept specific to architectural theory.

The spaces of each building define the building's identity. In other words, space gets interpreted by various users who often seek some form of authenticity, and that interpreted space becomes the identifier of architecture through preservation. The geographer Tim Cresswell defines space as an abstract concept that is a realm without meaning or attachment, i.e., a "fact of life." 43 This generic space becomes a "meaningful loca-

\footnotetext{
41 The quote is from an older version of the website, accessed 18 November 2017. "The Linden Centre," http://www.lindencentre. com/thelindencentre/; also see Berg, "Life with the Lindens"; Linden Centre " "Our Vision."

42 Berliner, interview with the author, 20 July 2015.

43 Cresswell, Place: A Short Introduction, p. 8.
} 
tion" when attachments, memories, and relationships are developed within the space. ${ }^{44}$ Places are therefore "repositories" for various interpersonal, community, and cultural relationships to develop and become attached to. ${ }^{45}$

Since place is culturally, politically, and socially constructed, it naturally reflects the ideologies of specific groups of people along with constant change. ${ }^{46}$ In other words, the connections between social groups and places are social relationships that change spatial arrangements. ${ }^{47}$ This makes the story of place one that involves inclusion and exclusion, inside and outside, tension and connection, and the reconstruction and imagination of boundaries that come with change. ${ }^{48}$ Moreover, this unstable push and pull dynamic of places make them sites of power struggles, displacement, and resistance, as well as sites that give a sense of meaning and significance to individuals, anchoring lives in dynamic social formations. ${ }^{49}$ This leads to what Timothy Oakes calls the "terrain upon which individuals act in attempts to secure a meaningful sense of spatial identity." ${ }^{50}$

44 Ibid., p. 7. "Meaningful location" as identified by political geographer John Agnew includes the three main aspects of (1) location, which refers to the objective coordinates of the site on the Earth's surface; (2) locale, which refers to the material setting and concrete form of the location; and (3) sense of place, which refers to the subjective and emotional attachment people have to the location.

45 Low and Altman have written about "place attachment" or the bonding of people to places and how it plays a role in "fostering individual, group, and cultural self-esteem, self-worth, and self-pride"; Low and Altman, "Place Attachment: A Conceptual Inquiry," p. 7. Summers emphasizes the social relationships particular to spatial works of art by using the word "observer" instead of "viewer" when expressing individuals who visit and occupy sites. This distinguishes visual arts that are meant to be viewed and looked at. "Observer" indicates the sense of not only seeing the work but knowing and examining the work and its setting with appropriate acts and behavior. Summers, Real Spaces, p. 42.

46 Low, "Cultural Conservation of Place," p. 67.

47 Summers, Real Spaces, p. 118.

48 Ibid., pp. 43, 56, 58. Summers continuously emphasizes the importance of spaces in relation to artworks. He asserts that all artworks were made for spaces and purposes that are different from that of the contemporary setting. Therefore "first spaces of use" are important to consider when learning about an artwork's history (p. 56)

49 Feld and Basso, "Introduction," pp. 5, 7.

50 Oakes, "Place and the Paradox of Modernity," p. 526. Oakes examines the unstable character of place by presenting two main components of a place: meaningful identity and immediate agency, both of which create a site with meaningful action for the individual. See page 510 for more on Oakes's discussion on what place is and what place is not. For more specific case studies, see Oakes, "Ethnic Tourism in Rural Guizhou."
The spatial transformation from space to place spurred by the preservation of authenticity is not completely dependent on the new identity that the stakeholders bring in to preserve the buildings. It also involves recognizing the inherent value present in the building. As stated by Jokilehto, the heritage of a site is something that exists only when someone recognizes it as such. ${ }^{51}$ Just as with any change that must happen, preservation efforts cannot be started without the careful observation of such a need. There is the act of recognition that must occur, and the decision to protect the present value prior to spatial transformation. For Yin Yu Tang and the Linden Centre, place identity was present in the original contexts for specific individuals and groups such as the Huang family and the Yang family, respectively, who may have found their identity in their houses. But this place identity drastically changed with the recognition of value from outsiders and new stakeholders, such as Berliner and Linden, and led to a new place identity and fertile ground for what I argue is the development of a framework of display.

One of the first steps in the transformation of Yin Yu Tang and the Linden Centre following the identification of inherent value is a conceptual (and physical in the case of Yin Yu Tang) extraction from context. This renewed place identity is a necessary step, because both structures cater to an audience unfamiliar with the cultures of rural China. Han Li discusses how Yin Yu Tang's re-contextualization in America keeps it an ordinary house of the Huang family, but simultaneously transforms it to take on new roles as a "cultural ambassador" representing the PEM's understanding of village culture, the PEM's cross-cultural relationships, and efforts at heritage preservation. ${ }^{52}$

Similarly, the Linden Centre highlights its new role by exuberantly and proudly displaying the local culture to outside visitors as "majestic traditions and gracious people that are China!" 53 Linden emphasizes the Linden Centre's vision to highlight the depth, richness, and delicate local culture threatened by increasing mass domestic tourism in China. ${ }^{54}$ The Linden Centre provides

\footnotetext{
51 Jokilehto, "Keynote Speaker Lecture."

52 Han, "'Transplanting' Yin Yu Tang to America," p. 57.

53 The Linden Centre, "Welcome to the Linden Centre."

54 Brian Linden, interview with the author, 17 May 2017, at the

Linden Centre, Xihou Town, Dali City, Yunnan, China. It should be noted that Linden considers himself more of an educator rather than a hotelier, pointing to the distinct visitor experiences that the Linden Centre offers.
} 
not simply a room for the night, but a place to experience and explore rural China. ${ }^{55}$ This process of extracting and highlighting curates the site into a specific, personalized, and elevated place for the visitor.

Once Yin Yu Tang and the Linden Centre are experienced by visitors, place attachment that is created by personal associations produces a "patina of affection." 56 For the museum visitor or tourist, both houses represent regional rural culture, but with the added layers of personal memories, experiences, and attachments. What they may have previously understood broadly as "China," now becomes a distinct place that they can relate to conceptually and identify physically. ${ }^{57}$ As the space is turned into a place, the buildings can then further develop into identities constructed and interpreted by the PEM or the Linden Centre team, as well as by the visitors to each site. All are considered stakeholders in the preservation process. This new place identity not only elevates the space from the ordinary to the extraordinary, but from a simple place to a "destination" with a sense of purpose, travel, and arrival.

Place and placemaking are critical, if not necessary, aspects of architecture. Christian Norberg-Schulz goes so far as to say, "the existential purpose of building (architecture) is therefore to make a site become a place, that is, to uncover the meanings potentially present in the given environment." ${ }^{8}$ Place involves "self-realization" where it is possible for various properties, uses, and interpretations to become uncovered and emphasized. ${ }^{59}$ Placemaking is therefore a process that continues as long as the physical environment has the capacity to create attachments in the minds of visitors through creating and invoking memories and imagination. ${ }^{60}$

For Yin Yu Tang and the Linden Centre, the display of authenticity has transformed the sites into curated and elevated places where visitors can identify, connect to, and learn about rural Chinese culture. How-

55 The Linden Centre, "Welcome to the Linden Centre." The website states that the Linden Centre is unlike an ordinary hotel, offering "direct access to timeless traditional communities." http:// www.linden-centre.com

56 Low and Altman, "Place Attachment: A Conceptual Inquiry," p. 2. Place attachment as a complex and multifaceted concept is defined as "the bonding of people to places" on social, psychological, and cultural levels; Fleming, The Art of Placemaking, p. 14.

57 Cresswell, Place: A Short Introduction, p. 7.

58 Norberg-Schulz, "The Phenomenon of Place (1976)," p. 422.

59 lbid.

60 Fleming, The Art of Placemaking, p. 17 ever, once a space becomes a place and placemaking begins in earnest, it is easy for the new place identity to overpower other identities inherent in the building, thereby hindering and even derailing the possibilities for the site to create new traditions based on preserved "original" identities. Therefore, when it comes to longterm preservation, the historical layers of a site must be sorted and prioritized. The essential key here is the attachment of the visitor within the placemaking process. Is there attachment to the sense of authenticity (defined through specific interpretations like those of the PEM or the Linden Centre) being displayed or the sense of tradition being preserved? The following section further examines this question by discussing placemaking through transnational and transcultural identity, both of which indicate an increasingly global outlook.

\section{The Present}

\section{- Placemaking and the Framework of Display}

The transformation of the place identity of Yin Yu Tang and the Linden Centre has pushed both buildings into a new spotlight that presents them as radical approaches to preservation. Both represent an outsider's vision of rural China that crosses national boundaries, while serving as "cultural ambassadors" that educate and entertain visitors in an accessible manner. This section explores the main difference between the preservation of the two buildings: while Yin Yu Tang focuses on protection, the Linden Centre focuses on forms of commodification. Ultimately, I argue that both of these approaches seek specific interpretations of authenticity through the framework of display.

\section{- Communicating the Intangible at Yin Yu Tang}

Yin Yu Tang primarily serves as a museum acquisition, albeit one that allows more intense interaction than many other objects in the collection. ${ }^{61}$ Preservation efforts in terms of extracting and highlighting have turned Yin Yu Tang into a new "place" to be ex-

\footnotetext{
61 PEM, "Daily Tours," https://www.pem.org/visit/daily-tours. Visitors to the PEM who would like to see Yin Yu Tang must purchase a separate entrance ticket. These are limited daily to ensure protection of the house and an ideal visitor experience.
} 
perienced by visitors at the PEM. In other words, it is a "meaningful location" with attachments, memories, and relationships intertwined in its make-up. ${ }^{62}$ As with many objects in the museum context, the house is no longer used in a conventional sense, and it is therefore no longer in danger of being demolished or renovated in an improper way. This raises questions regarding its identity as nonphysical, intangible culture. What has become of the traditions and expressions inherited from the past, such as knowledge, practices, and skills? ${ }^{63}$ Is the intangible identity of Yin Yu Tang nurtured? Or is it simply presented like any other artwork in an encased museum context?

The intangible culture of the Huizhou region is shared at the PEM through events like the annual Lunar New Year celebration along with daily activities like the complimentary audio guides that accompany visitors through the home, and the videos in the exhibition space adjacent to Yin Yu Tang. ${ }^{64}$ The audio guide explains the house's context and uses, and also includes direct personal accounts from Huang family members as they recount memories of their childhood, along with atmospheric sounds of Huizhou, such as people chatting, going about daily activities, or chanting in the ancestral hall. ${ }^{65}$ As long as one follows the cues and keeps listening to the audio guide, the encounter within Yin Yu Tang is engaging, educational, and easy to understand.

There are also three short films that play in a continuous loop titled Yin Yu Tang: A Chinese Home; Guo Nian: Passage in to a New Year; and Guo Men: A Village Wedding. These films include footage of traditional practices conducted in Huizhou such as a young couple's wedding, customs surrounding the New Year, and the beam-raising ceremony, which is a significant event that ensures blessings for the future inhabitants of a new home. Activities practiced in Huizhou are embedded together with footage of Yin Yu Tang's own

62 Cresswell, Place: A Short Introduction, p. 7.

63 UNESCO World Heritage Committee, "What Is Intangible Cultural Heritage?" UNESCO includes expressions such as "oral traditions, performing arts, social practices, rituals, festive events, knowledge and practices concerning nature and the universe or the knowledge and skills to produce traditional crafts" in intangible cultural heritage. The fragile character of intangible heritage is simultaneously traditional, contemporary, representative, and community-based.

64 PEM, "Ladies as Lions," https://www.pem.org/blog/ladies-aslions.

65 PEM, Yin Yu Tang House Audio Tour. moments of cultural experience and identity, such as the beam-raising ceremony that the PEM conducted in 2002 when Yin Yu Tang was re-erected on the museum grounds.

\section{- Communicating the Intangible at the Linden Centre}

The Linden Centre, on the other hand, began with the preservation of the Yang compound and renovation of its dilapidated Bai-style architecture to make it a place of cultural interaction and conversation. ${ }^{66}$ In contrast to Yin Yu Tang's re-contextualization in America, the Linden Centre has the advantage of utilizing the raw stimuli of being in the context of Xizhou and, like Yin Yu Tang, the physical and tangible heritage serves to create its contemporary identity, which includes various intangible cultural experiences curated for the guest. The horse stables at the back of the original structure have been converted to a third courtyard to allow for additional guest rooms. ${ }^{67}$ Other structural renovations mostly have to do with plumbing, electricity, and other needs for the comfort of visitors. ${ }^{68}$ According to Linden, renovations are kept to a minimum so that changes can be easily reversed. The focus of the Linden Centre therefore involves protecting its original identity found in its tangible heritage, but also seeks to reach an interpreted authenticity experienced through all five senses.

The intangible cultural experiences that are offered to visitors at the Linden Centre include cuisine, culture, handicrafts, and outdoor activities. Visitors who stay at the Linden Centre are encouraged to book and purchase these activities to enhance their experience. Specific activities include Dumpling Class, Three Course Tea Ceremony, and a Zhoucheng Tie Dye class within the Linden Centre property, as well as photography, market, and hiking tours. These classes and excursions are led by trained staff, both local and non-local.

I participated in the Three Course Tea Ceremony activity, Xizhou Market Tour, Dali City Tour, and the Linden Centre Tour, all of which were accompanied by the same member of the staff, Xiaoyun Yang, except for the

\footnotetext{
66 Brian Linden, interview with author, 17 May 2017.

67 Huang and Wu, "The Linden Centre: A Tour through Yang Pin Xiang's Home."

68 Brian Linden, interview with author, 17 May 2017
} 


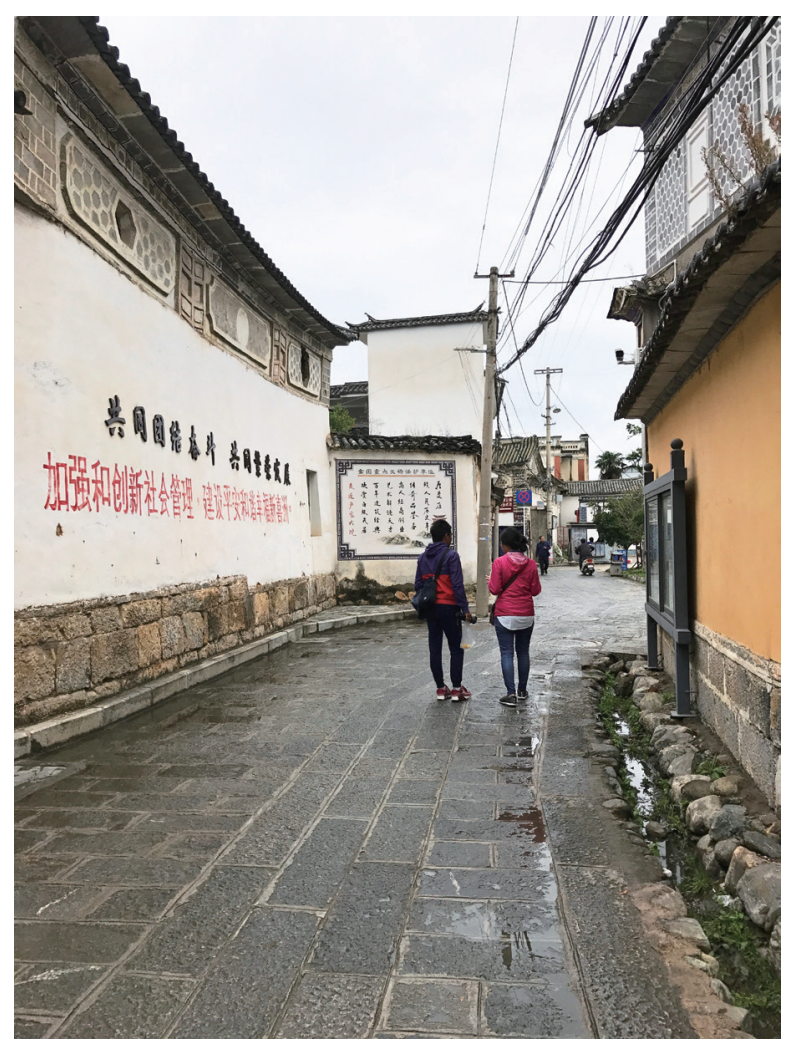

Figure 12. Xiaoyun Yang of the Linden Centre speaking about the new Linden Commons complex during the Xizhou Market Tour. Photograph by author. Permission of the Linden Centre.

Linden Centre Tour (figure 12). Yang, who is ethnically Bai, is originally from the nearby village of Nuodeng, went to university in Kunming, and later returned to the rural areas of Yunnan with an interest and sense of responsibility to preserve the local culture. Besides the Three Course Tea Ceremony activity, which was in the Linden Centre restaurant area, the two other activities were outside of the Linden Centre walls but were still very much within the guidance of the Linden Centre staff. Compared to the intangible cultural experiences that Yin Yu Tang offers at the PEM, which make the inactive into something active through the imagination, the experiences offered at the Linden Centre create a seamless personal narrative connected to the village of Xizhou. The intangible experiences seem to be a natural result of the surroundings of the Linden Centre and its Bai architecture instead of an indication of what is missing. The activities visitors experience are embedded into the surrounding environment, increasing the sense of experience in real time as well as authenticity.

\section{- The Metaphor of the Frame}

Yin Yu Tang and the Linden Centre's physical structure and aspects of its intangible culture are protected, controlled, and commodified through the framework of display. This metaphor of the frame is discussed by David Phillips as something that brackets experiences, and defines what is included and excluded while simultaneously "signaling the context that determines the meanings of whatever is included." ${ }^{69}$ Just as a picture frame functions to distinguish the contents, framing as a metaphor transforms reality by consciously distancing and shifting it through physical and social signs. Performances, ceremonies, rehearsals, and other social activities that involve a degree of pretense are the most common framed situations. A frame indicates the presence of a viewer with a specific gaze and an awareness of certain expectations, behaviors, meanings, and assumptions within the frame, making it essential to understand what the frame is in order to understand the subject it is framing. Phillips mentions that, "The frame is first of all a sign that whatever is represented within it is not a transparent view of reality, but a keyed representation," or a simulated experience. ${ }^{70}$

\section{- The Reframing of Yin Yu Tang and the Linden Centre}

Yin Yu Tang, as mentioned earlier, is a museum acquisition, physically placed in the center of the museum's courtyard. This means that the framework of Yin Yu Tang is the PEM. Museums are "displays of works of art, and at the same time displays about [museums], in which the works can play the role of illustrations to the argument of a book." 71 Although Yin Yu Tang carries a valuable and unique past, it has nevertheless been extracted from its original framework of Huizhou and reframed and inserted within the story of the PEM and its endeavors. This museum frame sets Yin Yu Tang apart from other Chinese vernacular forms of architecture and therefore it remains trapped within the presentation.

This does not mean that Yin Yu Tang fails to offer a

69 Phillips, Exhibiting Authenticity, p. 203.

70 Ibid., pp. 204, 206; see the same publication for more details on the complexities of the frame metaphor. 71 Ibid., p. 212. 
valuable and unique experience for visitors. Its presentation indeed strives to reveal layers of the home's physical and cultural history, but ultimately what it most lacks becomes the most unique and noticeable part of its contemporary identity as a re-contextualized, protected, and foreign object in a museum. The framework of display at the PEM indicates not only the presence of viewers and their gaze, but also a simulative and even performative character that is embodied in the events, audio guide, and visual presentation of the house by the PEM. This simulative and performative character is the result of inserting a space into a museum and furthering its process of placemaking, while also protecting it and emphasizing its authenticity.

All three methods of learning about Yin Yu Tangthe audio guide, films, and a tour-provide a strong content-based encounter and a highly organized and scheduled approach to ensure timely, convenient, and protected experiences of the house. These approaches also create an immersive experience for visitors, who encounter a continuation of Yin Yu Tang's intangible history from Huizhou and the Huang family. Simultaneously, the various strategies of explaining the house attest to the absence of knowledge, practices, and social relationships that were attached to it in its former context. They point to what is missing, distant, foreign, separated, and no longer active in the tangible structure of Yin Yu Tang and its physical contents. Furniture, utensils, and other decorative objects and images are placed in positions that take on the appearance of being "just used" by inhabitants, but they are also absurdly stagnant and frozen in time from the 1980s. ${ }^{72}$

Like other museum acquisitions and period rooms, the starting point of Yin Yu Tang is the tangible house, which signals the viewer to imagine and learn about the activities, relationships, sights, smells, and sounds that once occupied the place. The PEM has successfully recreated Yin Yu Tang as a new place within the museum, using it as a foundation and springboard to create a sense of authenticity for visitors. Because of the sheer uniqueness of an entire house being part of a museum collection, visitors easily digest and believe other characteristics of the house as part of the authentic identity of Yin Yu Tang. As Han Li discusses, the

72 PEM, Yin Yu Tang: A Chinese House, Frequently Asked Questions, $\mathrm{http}: / /$ yinyutang.pem.org/faqs.html. Sixty to seventy percent of the objects are original to the house. The other objects all come from homes with similar histories in the same region.
PEM has transformed the house's identity from a single dwelling to a "matrix of living scholarship of Huizhou architectural, cultural, and social legacies." ${ }^{3}$ Yin $\mathrm{Yu}$ Tang combines various time periods with both micro, or everyday, practices and macro, or socioeconomic, changes to create a "panoramic view" of "lived" history. ${ }^{74}$ Yin Yu Tang's presentation brings the experience to a convenient proximity but ultimately signals that the visitor is merely a visitor. Authenticity is also an experience interpreted by both the giver and the receiver, and the identity of Yin Yu Tang is built on the idea of displaying the different, the new, the unique, the endangered, and the exotic. Viewers can replace all aspects of this identity with their own understanding of what is most authentic to them.

Yin Yu Tang accommodates a broader audience by elevating a singular story into an accessible narrative that interweaves multiple cultural, societal, and national threads. In some ways, visitors' expectations are shaped by the institution as a truthful representation of Huizhou architecture and culture, just as a museum painting by Picasso represents various artworks that he created throughout his artistic career. It is merely a glimpse or a slice of what represents an entire identity.

The Linden Centre attempts this same elevation of the singular by engulfing the visitor into a reframed version of the building's history and Xizhou culture. The visitor is invited to participate in a "profound cultural experience," and asked to "Come for the culture ... come for the adventure."75 The Linden Centre exhibits a continuity that is believable and therefore accurate and authentic. The walls of a traditional museum may be torn down, but they are replaced by a wall that is camouflaged in its surroundings and curated to fit an experience that most visitors will have nothing to compare to.

As mentioned earlier, the metaphor of the frame is "a sign that whatever is represented within it is not a transparent view of reality, but a keyed representation," or a make-believe or simulated experience. ${ }^{76}$ The Linden Centre builds on the identity of Yang's compound, but it has been reframed like Yin Yu Tang through the framework of display. However, the reframing of the Linden Centre is much more discreet and caters to

\footnotetext{
73 Han, "'Transplanting' Yin Yu Tang to America," p. 59. 74 lbid.

75 The Linden Centre, "Welcome to the Linden Centre."

76 Phillips, Exhibiting Authenticity, pp. 204, 206.
} 
tourists, which raises the question of how the Linden Centre stages and performs authenticity.

\section{- Authenticity to Be Gazed At: The Visuality of Sightseeing and Tourism}

Oakes claims that place is an unstable terrain of modernity that is defined by paradox. ${ }^{77}$ Upon this paradox, Oakes discusses authenticity as an abyss, an empty void that is obvious yet ignored through tourist experiences. ${ }^{78}$ Yin Yu Tang manifests Oakes's paradox of authenticity by collapsing one site's past and present, distant and near, active and inactive, and the local and the global. But it concurrently emphasizes the original and truthful context of Huizhou that cannot be experienced and can only be simulated through recordings of surround sound and cycles of looped images. Daniel Knudsen, Jillian Rickly, and Elizabeth Vidon take a slightly different angle that more closely represents the type of authenticity sought by the Linden Centre. By focusing on humanity's sense of alienation, these authors claim that authenticity is the "self-rationalization that while one's life is missing all sorts of 'things,' they do exist elsewhere in other places/lifestyles/cultures." ${ }^{\prime} 9$ In this reading authenticity is a fantasy that is the fulfillment of desired and imagined enjoyment. It involves a personal journey, a seeking and hoping for something more. When a visitor is transformed into the specific sub-category of a tourist, as at the Linden Centre, fantasy and performative displays combine to feed, emulate, and recreate the tourist as an actively participating consumer. ${ }^{80}$

These views support the reframing of both Yin $\mathrm{Yu}$ Tang and the Linden Centre as seeking authenticity in tangible and intangible experiences. This also means that although there may be no velvet museum ropes placed throughout the spaces there is still a specific role and gaze designated for the visitor. At the Linden Centre, the visitor is more a participant who can interact with locals and play a role within an established and permanent place. This role is not only on the receiv-

77 Oakes, "Place and the Paradox of Modernity," p. 510.

78 Oakes, "Get Real! On Being Yourself and Being a Tourist," p. 233.

79 Knudsen, Rickly, and Vidon, "The Fantasy of Authenticity: Touring with Lacan," p. 42

80 Ibid., p. 43. I use the term "tourist" as a sub-category of visitor

that emphasizes the commercial and experience-based aspects. ing end of cultural experiences, but also on the giving end, which further strengthens the visitor's place attachment to the Linden Centre. In other words, it is the guests who ultimately experience and affirm the Linden Centre as an embodiment of the community's "cultural pride." ${ }^{81}$ The only thing expected of guests is their presence, which gives a sense of meaning and value to the Linden Centre. This role of the Linden Centre visitor contrasts with that of the Yin Yu Tang visitor who must deal with a multifaceted narrative of "lived" history and experience the here, the now, and the different at the same time. ${ }^{82}$

Dean MacCannell writes, "Sightseeing is a kind of collective striving for a transcendence of the modern totality, a way of attempting to overcome the discontinuity of modernity, of incorporating its fragments into unified experience." ${ }^{83}$ This mention of sightseeing clarifies the tourist context of the Linden Center within the framework of display as it immediately points to the viewing of a commodified object. Although there are many definitions regarding the business and marketing aspects of tourism, Jenny Chio defines tourism in rural China as a transformative experience for both tourists and hosts. Tourism involves sightseeing (or, in art historical terms, visuality), which includes the outward appearance of a place, human movement or mobility, and the various reasons and methods of travel. ${ }^{84}$ It is a socially constructed experience that is built around the idea of "how to be seen." 85 As Chio asserts, tourism is not just about leisure or money, but rather about perspective, representation, and imagination. ${ }^{86}$ At the Linden Centre, this is evident through the accentuation of its place identity as a "destination," which connotes what tourists seek: a place that offers exciting adventures and experiences that cannot be made at home. Notably, the leisure website Tripadvisor, a main portal to the Linden Centre for foreign tourists, describes the Linden Centre as "A destination, not a hotel" and as a

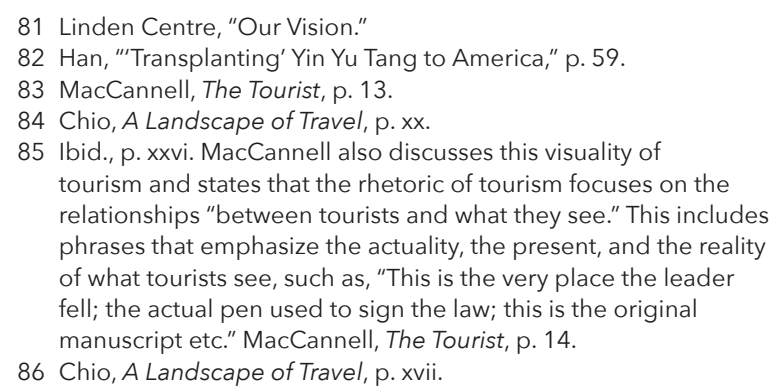


"destination to savor." ${ }^{87}$ The replies of the Linden Centre to reviewers' comments restate its identity as a destination created through a passion for cultural interactions. $^{88}$

During my stay at the Linden Centre, I observed other foreign visitors who appeared to enjoy the rich, raw culture of rural China in the village, while valuing the comfort and security of the Linden Centre as a home base. For many visitors, it is not just the village that is the destination of their voyage, but the specific experience of the village constructed by the Linden Centre.

Furthermore, the Linden Centre states that they challenge the conventional Chinese tourism model controlled solely by money. The Linden Centre believes that although they lack the modern amenities of other upscale hotels, "real travelers will decide to make it to our doorstep." ${ }^{9}$ The "destination" identity is what the Linden Centre desires, but it is simultaneously what most tourists also desire. Although the center may be going after certain kinds of tourists who are willing to go further out of their cultural comfort zones by trekking into rural China, they are nonetheless a hotel business that needs tourists in order to thrive. In "Life with the Lindens," Linden himself says that "we are selling the romance of old China" by using a language of commodification found within the framework of display. ${ }^{9 \circ}$

\section{- Performative Authenticity in Tourism}

Tourists motivated to see the unfiltered appearance of a different culture insert themselves in tourism's social constructs and then return home content or sometimes oblivious about their obviously inauthentic experienc-

87 Luo Kai, "A Destination, Not a Hotel," review of The Linden Centre, TripAdvisor, last modified 8 November 2017, https:// www.tripadvisor.com/Hotel_Review-g303781-d1421116Reviews-The_Linden_Centre-Dali_Yunnan.html. Original emphases; Baywanderer, "Even Better than Expected, review of The Linden Centre, TripAdvisor, last modified 31 May 2018, https://www.tripadvisor.com/Hotel_Review-g303781-d1421116Reviews-The_Linden_Centre-Dali_Yunnan.html; "Media and Awards," http://www.linden-centre.com/news/.

The Linden Centre has also received consecutive travel awards including the TripAdvisor Traveler's Choice Award from 2011-2019.

88 Luo, "A Destination, Not a Hotel."

89 Ibid., response by Brian Linden to Luo's review.

90 Berg, "Life with the Lindens," p. 48. es. ${ }^{91}$ MacCannell discusses sightseeing as involving both tourists and tourist sites in creating a single, transcendent wholeness, while also celebrating the differences and uniqueness of sites and experiences. ${ }^{92}$

Performative authenticity in both Yin Yu Tang and the Linden Centre stems from the social structure of tourism, as discussed by the sociologist Erving Goffman. In Goffman's analysis, the front is a place for visitors and the back is a place for the host. ${ }^{93}$ This clear separation of the front and back is sustained through mystification, which is inhabited by authenticity, which in turn generates a sense of reality. ${ }^{94}$

MacCannell also mentions that it is only when a tourist penetrates into local life and participates in the lives of others that he or she can experience genuine culture. ${ }^{95}$ This is where the Linden Centre becomes a fascinating place that appears to be an experience of the "back" sphere of Xizhou Village life. The architecture is contextual, many of the staff are locals, and the activities offered are intimate opportunities to personally engage with the local culture and its people. ${ }^{96}$ Compared to many other tourist sites, including the Yan family compound, the Linden Centre asks visitors to be much more active and engaged. ${ }^{97}$ They are not at the Linden Centre to simply see an attraction but to live in a tradition. If the Linden Centre's visitors are so engaged, welcomed, and encouraged to participate, how is it that they are possibly placed within a performed and staged back sphere, within the framework of display that seeks authenticity?

\footnotetext{
91 MacCannell, The Tourist, p. 94.

92 Ibid, p. 13. MacCannell's chapter titled "The Evolution of

Modernity" presents his discovery that "sightseeing is a ritual performed to the differentiations of society." The differences in each community function as attractions that can be discovered or reconstructed.

93 Ibid., p. 92.

94 Ibid., p. 93

95 Ibid., p. 106.

96 Zhu, "Cultural Effects of Authenticity," pp. 596-97. The Linden

Centre plays on creating an experience that is authentic through embedding opportunities to have interpersonal interactions that have to do with individuality and identity. Along with this type of experience that can be referred to as "existential authenticity," the Linden Centre also involves the performative approach which emphasizes the process of developing qualities of authenticity (p. 596).

97 The Yan family compound is a short walk from the Linden Centre in the market square of Xizhou. It is the former home of the wealthy Yan family and was built in the 1920s. It is preserved and presented as a museum that houses a collection of Bai decorative objects, paintings, and furniture. Visited by the author on 14 October 2016 and 16 May 2017
} 
MacCannell states that within a tourist setting, instances when a visitor peeks into the real back sphere by having an "experience" occur by accident. ${ }^{98}$ During my stay at the Linden Centre, I participated in the offered cultural experiences, which are meant to give glimpses of the back sphere, but I also went on my own excursion outside of the hotel walls with no destination in mind. The moment I stepped outside of the Linden Centre, I came to the realization that I was on my own and no longer a participant in the Linden Centre narrative that was guided, shielded, and entertained by the Linden Centre's curated activities. ${ }^{99}$ Was I still within the broader tourist's display framework? In other words, was I simply viewing a form of authenticity that was just slightly offstage but not in the back sphere? That may very well be the case, but nonetheless, the context of the Linden Centre is intentional, preorganized, preplanned, and intended to be seen by consumers. However, unlike Yin Yu Tang, the display framework is less visible and much more delicate. This is evident through some degree of spontaneity included in the organized tours as they are intimate excursions that include interactions with outside events and locals, making every tour a slightly different experience. Visitors can also, at their own will, exit the framework to experience $\mathrm{Xi}$ zhou outside of the Linden Centre's display framework, which could still mean that remnants of the Linden Centre will consistently follow.

The experiences and atmosphere offered at both Yin Yu Tang and the Linden Centre are presented in a way that fulfills a sense of encountering the "extraordinary," whether through re-contextualizing the building for preservation or re-contextualizing the visitor for commodification. ${ }^{100}$ These ideas of authenticity lead them to embody fantasies that are important concepts filled with the desire to complete something beyond their reach. ${ }^{101}$ The fact that both Yin Yu Tang and the Lin-

98 MacCannell, The Tourist, p. 97.

99 On my own excursion in May 2017 I ran in to one of the Linden Centre staff by chance as she was casually chatting with her neighbors. Although I knew she was a local resident, it oddly felt like I was seeing a performer off stage, who lacked a tag with her name in English accompanied by the Linden Centre logo. Seeing a member of the community resting and relaxing in her neighborhood meant abandoning the Linden Centre filter and simultaneously putting myself in a much more conscious observer position.

100 Knudsen, Rickly, and Vidon, "The Fantasy of Authenticity," pp. $35,41$.

$101 \mathrm{lbid} .$, p. 37 den Centre are reframed so that activities and representations are curated especially for the visitor's gaze and consumption places them within the framework of display. As Knudsen mentions, "The commodification of experience is central to tourism, as an industry in which the destination is the product that is crafted and marketed through the 'experience economy.' "'102 The experiences, especially at the Linden Centre, are practices of performative authenticity for both visitor and host. ${ }^{103}$ As MacCannell confirms, the commodified experience functions in modern society as a means to an end that is the "immense accumulation of reflexive experiences which synthesize fiction and reality into a vast symbolism, a modern world." 104 The intentional and the accidental, as well as the organic and the planned, all become blurred into one experience that makes the entire Linden Centre stay symbolic of an authentic exploration of Xizhou.

Museums are described as ritual sites that evoke a sense of "liminality" or the temporary mode of consciousness that sets one outside of everyday life. ${ }^{105}$ I would argue that the framework of display has a similar effect. The Linden Centre website repeatedly assures and alerts the visitor that their stay will provide "an immersive experience into the rich, living communities of China's countryside" and embody an "enlightened immersion into rural China." ${ }^{106}$ These mental preparations are comparable to an audience asked to be quiet and turn off all electronics in order to protect the "fourth wall," or frame of display, from shattering in a theater. Furthermore, this liminal experience is linked to the guests who are invested in giving life to the hotel since it gives greater value to their own experience. ${ }^{107}$ It is safe to say that what visitors are attracted to in Yin Yu Tang and the Linden Centre is the sense of displayed authenticity (defined through specific interpretations by the PEM or the Linden Centre) rather than preserved tradition. This is also connected to the idea of authenticity

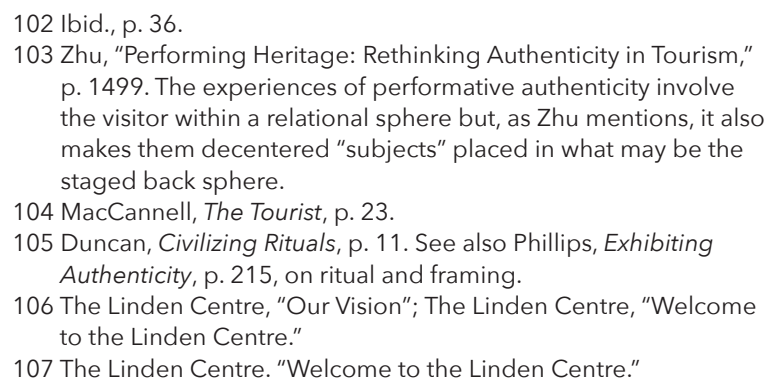
p. 1499. The experiences of performative authenticity involve the visitor within a relational sphere but, as Zhu mentions, it also makes them decentered "subjects" placed in what may be the staged back sphere.

104 MacCannell, The Tourist, p. 23.

105 Duncan, Civilizing Rituals, p. 11. See also Phillips, Exhibiting Authenticity, p. 215, on ritual and framing.

106 The Linden Centre, "Our Vision"; The Linden Centre, "Welcome to the Linden Centre."

107 The Linden Centre. "Welcome to the Linden Centre." 
as something that is constantly in a state of becoming. It is always in process, fluid, and transformative. The dynamics of "becoming" authentic through display and performance leads us to the idea of authentication. ${ }^{108}$

\section{The Future}

\section{- Authentication and the Process of Becoming}

As discussed above, the process of placemaking in Yin Yu Tang and the Linden Centre seeks authenticity through the material tangibility of the architecture, which in turn lends authority to the intangible culture they embody. For Yin Yu Tang, this authenticity manifests in protection, and for the Linden Centre, it manifests in commodification. Each manifestation of authenticity results in displays of the extraordinary, the exotic, and the genuine. This is linked to the concept of authentication, which instead of simply viewing authenticity as a set of fixed characteristics, connotes a social process in a constant state of flux. ${ }^{109}$

This also sheds light on the power relations involved in authenticity. For both Yin Yu Tang and the Linden Centre, the "power of authentication" is given to a variety of stakeholders, including visitors and the larger heritage organizations. ${ }^{110}$ Ultimately, however, power starts with the creator of the new framework at each site, namely the PEM and Linden. Both sites have their own interpretations of authenticity, and this reveals the necessity for authenticity to be cultivated and built upon in order to remain effective. Ultimately, authentication helps shed light on the placemaking identities of Yin Yu Tang and the Linden Centre as processes that involve conscious actions by the stakeholders to develop these identities.

When Yin Yu Tang and the Linden Centre are viewed through authentication, they become places in progress that represent aspects of their original identities, and negotiate new standards and expectations. For Yin Yu Tang, expectations include committing to a clean, safe, and accessible educational environment that is in line with museum standards in the US. ${ }^{111}$ For the

108 Zhu, "Performing Heritage," p. 1498.

109 Zhu, "Cultural Effects of Authenticity," p. 597.

110 lbid., p. 596.

111 Accessible here means easy to travel and navigate through but also in line with the Americans with Disabilities Act (ADA)
Linden Centre, expectations are in line with those for museums, but because it is a hotel, it must also provide a hands-on cultural experience that will keep visitors occupied, comfortable, and interested during their stay. The Linden Centre must also fulfill the expectations of the local Chinese government involved in supporting the Centre, which Brian Linden mentioned as challenging since his foreign roots bring attention to both successful and unsuccessful outcomes of operating a hotel that is also a heritage site. ${ }^{112}$ The process of authentication reveals what is desired in touristic settings, which is a romanticized interest in what is natural, rural, and ethnic. Both sites must keep up to date with the most recent trends in tourist desires or else the framework of display that they thrive within will shatter and the discontinuity of reality will become evident and break the spell of authenticity.

Yujie Zhu asserts that authentication has three separate phases of construction: "spatial separation," "emotional banishment," and "value shifting." ${ }_{113}$ Although he is speaking more about the authentication of sites formulated by global heritage agencies such as UNESCO and its advisory boards, the same phases are visible at Yin Yu Tang and the Linden Centre. For example, "spatial separation" is the clarification of spatial boundaries of the site through isolation and "museumification" to prepare the site and its objects as an exotic spectacle for display. ${ }^{114}$ This phase is clearly what Yin Yu Tang embodies as an isolated and re-contextualized house that is demarcated for visitors to experience. The Linden Centre's "spatial separation" is more ambiguous, but it is similarly reframed as an object of consumption designed by a nonlocal for nonlocals. Instead of the object it is the viewer who becomes re-contextualized.

"Emotional banishment" refers to the validation given to the site such as objective evidence, laws, and judgments of authenticity, rather than the contextual practices and personal experiences related to the site. Both Yin Yu Tang and the Linden Centre actually engage in efforts to present social history, local community, and intangible culture related to each site, but as discussed before in "The Present," they depend on

guidelines. For more information on ADA guidelines, see Department of Justice, "Information and Technical Assistance on the Americans with Disabilities Act," ADA.gov, https://www.ada. gov/2010_regs.htm.

112 Brian Linden, interview with author, 17 May 2017.

113 Zhu, "Cultural Effects of Authenticity," pp. 603-604.

114 lbid. 
tangible evidence to provide a narrative that covers a number of aspects within Chinese culture. "Value shifting" refers to the label of "authenticity" or "authentic" given to a site that not only changes its economic value, but also the public view and moral judgment of a site. Yin Yu Tang and the Linden Centre fulfill this phase as they "value shift" from wealthy merchants' homes to tourist sites with a fresh audience, elevated status, and contemporary function. These phases of authentication clarify that the placemaking purpose of Yin Yu Tang and the Linden Centre focuses on viewers in a continual process of consuming, discovering, and desiring the unattainable.

\section{- The Creation of Tradition}

The concept of tradition is an act of transmission that continues with a persisting central identity despite other changes. ${ }^{115}$ In this view, Yin Yu Tang's process of authentication presents traditions as a recreated display of "pastness," or a nostalgia for what has never been experienced before. ${ }^{116}$ Yin Yu Tang's stable presentation is based on a lack of active or fluctuating changes in the uses and appearance of the house today. The Linden Centre is more active, and focuses its place identity on past traditions as well as developing traditions in the present and future as a boutique hotel.

Arguably, both Yin Yu Tang and the Linden Centre follow the definition of heritage as "not an inquiry into the past, but a celebration of it." "17 Yin Yu Tang may seem like an inquiry into the past as a museum exhibition, but it also carries a sense of celebrating the success of overcoming dangers it once faced before being rescued by the PEM. There is an underlying assumption that the PEM has already taken care of stabilizing endangered Huizhou culture in a safe museum environment, which gives Yin Yu Tang permission and credibility to stand with pride as an exemplary achievement. On the other hand, the Linden Centre focuses on creating something that can be built upon and continued for further gener-

115 Shils, Tradition, pp. 12, 14.

116 Weiler, "Aspects of Architectural Authenticity," p. 219; Lowenthal, "The Past as a Theme Park"; Shils, Tradition, p. 13; MacCannell,

The Tourist, p. 34. Tradition can also be discussed as a "position of servitude: Tradition is there to be recalled to satisfy nostalgic whims or to provide coloration or perhaps a sense of profundity for a modern theme" (MacCannell, p. 34).

117 Harrison, "What Is Heritage?," p. 10. ations as it continues its journey of presenting the Linden brand of radiating authenticity. There is a stronger sense of never-ending placemaking at the Linden Centre. Authentication is a core process at each site, formulating new identities within contemporary frames and functions of display.

\section{- The Future of Placemaking}

The preservation of a built environment requires incorporating past traditions with new traditions to maintain a site as useful and valuable for future contexts. However, the main challenge of preservation is balancing past and future identities. There must be both for a structure to sustain its history, while also sharing its legacy with future generations. Space is a distinguishing characteristic of architecture, one that indicates the past, the present, and the future functions of the building. It is essential to take into consideration how space has changed in terms of form and function. Yin $\mathrm{Yu}$ Tang and the Linden Centre, both of which were formerly used as residences placed within a specific family history, context, and narrative, have become a museum and a hotel respectively. They are run as part of larger organizations and businesses that depend on the gaze and participation of outsiders, which have become the main force fueling their contemporary identities. They are forms of art to be looked at, to be entered into temporarily, to be experienced as exotic yet comfortable, and to be exited smoothly and conveniently with neatly packaged memories free of responsibility or commitment to the site upon departure.

Tradition is created in each structure, but it is no longer the tradition of the local community and villagers. Rather, it is the tradition imagined and orchestrated by outsiders such as the staff at the PEM and Linden. Each leader in this creation of tradition intends to save the bounty of knowledge and culture contained within the structures, but the act of creating tradition is somewhat separated from the visitors. Although tourists play a part in creating the Yin Yu Tang or Linden Centre experience, they are mostly there to receive, to consume, and to leave. If anything, the visitors and locals in Xizhou or Huizhou have the key role to prove and give credit to the tangible authenticity of the structure and its performed aura of authenticity, contributing to pushing forth the process of authentication.

The preservation approaches of both Yin Yu Tang 
and the Linden Center also reveal the existing qualms from different individuals involved in the projects. Bonnie Burnham, former president of the World Monuments Fund, worries that Yin Yu Tang's preservation approach "is a collector's instinct, not necessarily a preservationist's instinct." ${ }^{118}$ She emphasizes the physical extraction of Yin Yu Tang as a controversial approach to saving and protecting it. Additionally, John Waite, the project architect after Yin Yu Tang was dismantled, highlights the extenuating circumstances of similar houses in the region facing destruction. ${ }^{119}$ Some of the threats that concern Waite are the new hotels and tourist attractions in the area. ${ }^{120}$

Interestingly, the Linden Centre is one such hotel that was not built as new, but rather renovated as a response to preserving the endangered buildings in the area and maintained through tourist revenue. Existing qualms about the Linden Centre mostly have to do with its function as a business. Although reviews of visitor experiences by both foreign and Chinese visitors are extremely positive, some locals and architecture experts have mentioned that the building is no longer a traditional Bai compound but a commoditized heritage site. Furthermore, there are questions about the vague association between the Linden team and government officials, who are oftentimes the force pushing historic houses into tourist sites. ${ }^{121}$ Many locals trust Linden and his leadership, but information regarding the funding, profits, and work allocation of the Linden Centre remain undisclosed. ${ }^{122}$

Despite these criticisms, Yin Yu Tang and the Linden Centre each present a form of Chinese culture that carries on past identities and traditions, representing important examples of what Chinese vernacular architecture is like to a wider audience. Their presence instills a sense of security within an unstable reality, where ethnic heritage in vernacular architecture is oftentimes bound to fade away and therefore reveals a need to be protected and experienced if at all possible.

118 Tracie Rozhon, "Moving House, With 2,000 Chinese Parts," New York Times, 2001.2.22, http://www.nytimes.com/2001/02/22/ garden/moving-house-with-2000-chinese-parts.html.

$119 \mathrm{lbid}$.

$120 \mathrm{lbid}$.

121 Zhao, "'China's Leading Historical and Cultural City," p. 110. The Linden Center is operated through a public-private partnership or PPP, which Zhao describes is more of a government-private nexus in which the local government does not represent the general public but has an extended partnership with Linden. 122 lbid., p. 110.
They each signal the hidden value found in architecture as well as the rising awareness of contemporary viewers who want opportunities to connect, participate, and see the culturally removed yet preserved relics of the past. This gives visitors access to a "transcendent consciousness" that creates a unified sense of place, despite the reality of placelessness that exists within disparate experiences. $^{123}$

Both Yin Yu Tang and the Linden Centre will have to be increasingly careful in how they look back to their roots in rural Chinese culture as they take on the assumed role of promoters of preservation and tourism in rural China. Tourist interest in rural villages is growing, leading to a nationwide increase in minsu 民 宿, or family-owned inns. Minsu can provide a unique and educational experience for many visitors, but they are also becoming a business market where traditional vernacular architecture can become exploited. ${ }^{124}$ It is important for the main stakeholders of each site to remember that Yin Yu Tang and the Linden Centre are examples of preserved heritage that can serve as signs to a rich culture, but they should not solely be seen as models to copy and follow. ${ }^{125}$ The specific context, culture, needs, and abilities of the site and stakeholders requires careful consideration so that the transformation of houses to hotels or tourist destinations does not simply become a profession and temporary business endeavor targeting gullible tourists. ${ }^{126}$

More importantly, both structures are singular ex-

\footnotetext{
123 MacCannell, The Tourist, pp. 13, 15. MacCannell states that "tourism and participation in the other modern alternatives to everyday life makes a place for unattached individuals in modern society" (p. 15).

124 CGTN (China Global Television Network), "The Rise of the Minsu," 43:56, YouTube video, posted by CGTN 14 July 2018, https://www.youtube.com/watch?v=F1Cm2TfwzGs. 125 CGTN, "The Rise of the Minsu."

$126 \mathrm{lbid}$. As discussed in the television program, in which Linden appears as a minsu operator, minsu in China are increasingly becoming a gateway to "rural revival" (43"), calling individuals back to the countryside to experience local culture. Linden mentions that minsu must not focus on the business of design and luxury but incorporate people with passion and skill, providing an experience specific to the culture. The Linden Centre does strive for all of these things, but the very fact that they are being considered a successful and perhaps leading model of the sustainable minsu business clashes with some ideas of preservation that do not solely depend on incoming revenue and attention. The popularity of minsu also explains the increase in hotels that are similar to the Linden Centre in the surrounding neighborhoods, many of which prioritize leisure and comfort more than the Linden Centre. See one example here: http://www.skyvalleyhotel.com/home.
} 
amples that serve as signs for a greater need, that is the large-scale, long-term preservation of architecture built by and for a past that is quickly and quietly vanishing. In these cases, the framework of display will only be effective for so long. The framework of display thrives on being seen, and when the attention of visitors dries out, it will try to reinvent another level of authenticity to attract and contain its status as an object to be viewed. Although display certainly plays an important role in greater visibility, and hence awareness of preservation, it also poses dangerous pitfalls that can easily lead to a site being a commodity that solely keeps up with needs and desires that are ultimately artificial, hyperreal semblances of a culture. ${ }^{127}$

Placemaking at Yin Yu Tang and the Linden Centre reveals that they are each seeking an ideal representation within the framework of display. Ultimately, new values and meanings are produced for consumption that makes authentication the tradition. ${ }^{128}$ This article demonstrates that authenticity has a plethora of approaches, all of which point to its ultimate unattainability. It is a desired ideal, but like many ideals, constantly remains a figment of the imagination.

\section{Conclusion}

Yin Yu Tang at the PEM and the Linden Centre in Xizhou are two artworks and architectural subjects that have gone through profound transformations in function, impression, and meaning. They have both crossed over from being private sites to public sites, from permanently occupied places to temporarily occupied destinations, and from enclosed homes of generational families to porous attractions to be visited, looked at, learned from, consumed, and departed from. The knowledge available to visitors at each of these sites uses a method of attraction that breaks from conventional museum and hotel practices, as they encourage the visitor to not only observe, but to listen, move, and interact with the richness of the buildings and their cul-

\footnotetext{
127 Botz-Bornstein, "Hyperreal Monuments of the Mind," p. 7.

128 Phillips, Exhibiting Authenticity, p. 215. Phillips argues that liminal sites such as museums and television present the desire for a personal authenticity that refuses to compromise with the devices of daily social life. Contemporary society mistakes this yearning for authenticity with the authenticity of objects themselves which makes museums an ideal and significant site to fulfill these needs.
}

tures. I have argued that the two houses illustrate the difficult intersection of preservation and authenticity, which uses re-contextualization as an essential and ultimately advantageous element to develop, attain, and cultivate an authenticity found within the framework of display. This has been demonstrated by focusing on the transformation of space to place, the placemaking of Yin Yu Tang and the Linden Centre through framing, and the consistently changing nature of authentication.

At times, authenticity is defined as genuine. At other times, it is the new, the immersive, or the exotic. At yet other times, it attempts to capture the identifiers of context, genius loci, and the passage of time. ${ }^{129}$ The meaning of authenticity is constantly expanding and adapting to particular circumstances and viewers. Constant visibility leads to greater believability. Despite its ultimate unattainability, authenticity has an important function that reveals the universal desires of travelers and museum-goers as well as the core rationales that entire tourism industries revolve around. It acts as a powerful impetus to push forth placemaking at culturally significant sites. And when placemaking stabilizes, a sense of attachment, belonging, and anchoring can be attempted and satiated even if it is for a temporary period.

For Yin Yu Tang and the Linden Centre, re-contextualization serves to develop placemaking focused on an authenticity that also promotes preservation. Yin $\mathrm{Yu}$ Tang creates an awareness of the need for preservation due to an increase in tourism and the building of new hotels and attractions in rural villages like Huizhou. However, it creates this awareness through the physical removal of a building for display. This is a rather drastic move that does not directly yield to preservation in the wider context. In contrast, the Linden Centre has converted an existing structure for new uses, but it is also responding to rising tourism in the area. Each structure went through a process of exposing the site, then elevating its newly rescued status, and then unifying its past, present, and future. The outcome is a cultural product that may be attributed the double function of a sign and a ritual: a sign intended for raising awareness of the endangered Chinese vernacular architecture, and

\footnotetext{
129 For more on genius loci ("spirit of the place") and its connections to concepts of "atmosphere" and "aura," see Petzet, "Genius Loci-The Spirit of Monuments and Sites," p. 63. See also RicklyBoyd, "Authenticity \& Aura."
} 
a ritual that celebrates differences and juxtapositions. ${ }^{130}$ This outcome is impactful and presents an innovative and imaginative model of architectural and cultural preservation, but one that is actually distant from the true lifestyle and reality of the culture. ${ }^{131}$ In other words, both buildings create preservation awareness, but are simultaneously fueled and funded by protection and commodification, a tension that is ever present in architectural preservation. Their traditions appear to present a history and experience that is clear and continuous, but actually offer a study of spatial transformation within transnational and transcultural encounters. ${ }^{132}$

Yin Yu Tang and the Linden Centre present many comparative differences, including the promotion of an authenticity that masks either protection or commodification. A similarity that surfaces is the issue of localized authenticity creating commodification. By localized authenticity, I am referring to the connection that is created between the contemporary identities of Yin Yu Tang and the Linden Centre to their current surroundings. There is evidence of each site being deliberately chosen and consciously cultivated to connect to current environments and provoke certain responses. Yin Yu Tang was chosen partly due to the presence of other nineteenth- and twentieth-century homes exhibited by the PEM, which is a "pioneer in the acquisition, relocation, restoration, and interpretation of historic environments." ${ }_{133}$ With the accession of Yin $\mathrm{Yu}$ Tang, the PEM has achieved new heights in architectural preservation.

Linden similarly chose the Yang compound and $\mathrm{Xi}$ zhou in Yunnan as a prime site and location due to its relatively solitary and rural environment that has not yet been invaded by waves of domestic and international tourists. It too has a history of being part of a network of trade through the ancient tea-horse road, which extended from southern Yunnan to Tibet, carrying tea, silk, and textiles from the late 1600 s to the

130 MacCannell, The Tourist, pp. 26-27.

131 Ibid., p. 32; Mike Ives, "From Outsiders to Innkeepers in China's Sleepy Countryside," New York Times, 13 August 2013, https:// www.nytimes.com/2013/08/14/business/global/in-chinascountryside-travelers-find-foreigner-run-hotels.html.

132 Upton, "The Tradition of Change," p. 14. Upton discusses the need to bring more research away from the search for the authentic in vernacular architecture and landscape studies to the ambiguous, multiple, contested, and changing landscapes.

133 PEM, "Historic Houses," https://www.pem.org/visit/historichouses. mid-twentieth century. ${ }^{134}$ Yang's compound also presented the opportunity to create an unusual, far from mainstream experience of China through the focus on Bai culture. ${ }^{135}$ By choosing a Bai-style structure, the Linden Centre anticipates tourism that desires an ethnic experience, resulting in a localized authenticity. Here, it is apparent that authenticity broadly captures identifiers that are not only unique and different, but local and vernacular. Just as the term "organic" may procure a sense of pure and local production, a site that has immediate connections to the surroundings and vernacular heritage procures a sense of truthfulness, when in reality, it may just be a glorified and manufactured version of reality.

I would like to end by emphasizing that preservation is an effort that must be approached through various ways instead of one set method. Yin Yu Tang creates the awareness of preservation to a foreign audience, yet does not directly affect long-term preservation, which is the creation of new traditions. The Linden Centre involves the creation of new traditions in the future through its expanding brand and by engaging activities with various partnerships, yet can easily evolve into a business venture. Both buildings will always carry the challenging dynamic of preservation and authenticity as well as protection and commodification. Referring to the reconstruction of cultural heritage sites after wartime destruction, Phillips recognizes that, "it is the relentless transience of things that makes the ones we do preserve so precious, but we can ultimately no more arrest the process than we can transcend our own deaths by having ourselves embalmed, or frozen." ${ }^{136}$

As Yin Yu Tang and the Linden Centre age with time, their mud walls, wooden ceilings, and stone floors have come in contact with various occupants and their needs, demands, and hopes. Spaces that once reflected the gazes of family members going about their daily

\footnotetext{
134 "Accommodation," http://www.linden-centre.com/ accomodation_area/xizhou-en; Mike Ives, "Following the Ancient Tea-Horse Road. Or at Least Trying," New York Times, 25 July 2016, https://www.nytimes.com/2016/07/25/travel/chinaancient-tea-horse-road.html.

135 Sigley, "The Exemplary Foreigner: An Interview with Brian Linden," China Watch 2050 (blog), 12 May 2016, http://www. chinawatch2050.com/the-exemplary-foreigner-an-interviewwith-brian-linden; WildChina, "Interview: Brian Linden of the Linden Centre," Wild China (blog), entry posted 23 August 2010, https://www.wildchina.com/blog/2010/08/interview-brianlinden-of-the-linden-centre/.

136 Phillips, Exhibiting Authenticity, p. 129
} 
lives with dreams for future generations to prosper and multiply have been replaced with multilayered hopes aligned with an increasingly transnational and global outlook for more opportunities to connect, travel, and understand differences. The authenticity that is created clearly fulfills the contemporary needs of the stakeholders, while only partially pointing to future needs of the buildings as they are busy thriving within the frame of display. Today, the spaces reflect the observant and awed gaze of the visitor, the careful collector, the ambitious explorer, and the curious seeker always in search of what is fresh and what is old. Authenticity is perhaps an essential element in the placefinding journey that all of humanity can relate to, with the glimpses and mirages of its true form just enough to continue desiring. Yin Yu Tang and the Linden Centre illustrate the complexity of preservation and serve as a point of departure in examining the future landscape of heritage preservation on a global scale.

\section{Reference List}

Azuma, Mariko. "Yin Yu Tang and the Effects of Recontextualization on Vernacular Architecture." Senior Honors Thesis, The University of Utah, 2016. https:// collections.lib.utah.edu/details?id=205661.

Berg, Caroline. "Life with the Lindens." The World of Chinese 1:2 (2011), pp. 48-51.

Berliner, Nancy. Yin Yu Tang: The Architecture and Daily Life of a Chinese House. Rutland: Tuttle Publishing, 2013.

Botz-Bornstein, Thorsten. "Hyperreal Monuments of the Mind: Traditional Chinese Architecture and Disneyland." Traditional Dwellings and Settlements Review 23:2 (2012), pp. 7-17.

Chio, Jenny. A Landscape of Travel: The Work of Tourism in Rural Ethnic China. University of Washington Press, 2014.

Cresswell, Tim. Place: A Short Introduction. Short Introductions to Geography. Malden: Blackwell Publishing, 2004.

Domicelj, Joan. "Authentic? Nara Revisited...” In Conserving the Authentic: Essays in Honour of Jukka Jokilehto, ed. Nicholas Stanley-Price and Joseph King, pp. 143-52. Rome: ICCROM, 2009.

Duncan, Carol. Civilizing Rituals: Inside Public Art Museums. New York: Routledge, 1995.
Feld, Steven, and Keith H. Basso, eds. "Introduction." In Senses of Place, pp. 3-11. Santa Fe: School of American Research Press, 1996.

Fleming, Ronald Lee. The Art of Placemaking: Interpreting Community Through Public Art and Urban Design. London: Merrell Publishers, 2007.

$\mathrm{Fu}$, Xinian, and Nancy S. Steinhardt. Chinese Architecture. Yale University Press, 2002.

Han, Li. “'Transplanting' Yin Yu Tang to America: Preservation, Value, and Cultural Heritage." Traditional Dwellings \& Settlements Review 25:2 (2014), pp. 53-64.

Harris, John. Moving Rooms. Yale University Press, 2007. Harrison, Rodney. "What Is Heritage?" In Understanding the Politics of Heritage, ed. Rodney Harrison, pp. 5-29, 36-39. Manchester University Press in association with the Open University, 2010.

ICOMOS. International Charter for the Conservation and Restoration of Monuments and Sites (The Venice Charter 1964). Venice, Italy, 1964. https://www.icomos.org/ charters/venice_e.pdf.

ICOMOS. The Nara Document on Authenticity (1994). Nara: ICOMOS, 1994. https://www.icomos.org/charters/nara-e. pdf.

Jiang, Yangyang, Haywantee Ramkissoon, Felix T. Mavondo, and Shanfei Feng. "Authenticity: The Link Between Destination Image and Place Attachment." Journal of Hospitality Marketing and Management 26:2 (2016), pp. 105-24.

Jokilehto, Jukka. A History of Architectural Conservation. Oxford: Butterworth-Heinemann, 2001.

Jokilehto, Jukka. “Keynote Speaker Lecture: Questions of Authenticity Concerning Different Cultures and Preservation." Speech given at the International Congress, Preserving Transcultural Heritage: Your Way or My Way? ARTIS Institute of Art History, School of Arts and Humanities, University of Lisbon, 5 July 2017.

Knudsen, Daniel C., Jillian M. Rickly, and Elizabeth S. Vidon. "The Fantasy of Authenticity: Touring with Lacan." Annals of Tourism Research 58 (2016), pp. 33-45.

Lamprakos, Michele. "Riegl's 'Modern Cult of Monuments' and the Problem of Value." Change Over Time 4:2 (Fall 2014), pp. 418-35.

Low, Setha M. "Cultural Conservation of Place.” In Conserving Culture: A New Discourse on Heritage, ed. Mary Hufford, pp. 66-77. University of Illinois Press, 1994.

Low, Setha M., and Irwin Altman. "Place Attachment: A Conceptual Inquiry." In Place Attachment, ed. Setha M. 
Low and Irwin Altman, pp. 1-12. New York: Plenum Press, 1992.

Lowenthal, David. “The Past as a Theme Park.” In Theme Park Landscapes: Antecedents and Variations, ed. Terence Young and Robert Riley, pp. 11-23. Washington: Dumbarton Oaks Research Library and Collection, 2002.

MacCannell, Dean. "Staged Authenticity: Arrangement of Social Space in Tourist Settings." American Journal of Sociology 79:3 (1973), pp. 589-603.

MacCannell, Dean. The Tourist: A New Theory of the Leisure Class. University of California Press, 1999.

Nochlin, Linda. “The Imaginary Orient." Art in America IXXI:5 (1983), pp. 118-31.

Norberg-Schulz, Christian. "The Phenomenon of Place (1976)." In Theorizing a New Agenda for Architecture: An Anthology of Architectural Theory, 1965-1995, ed. Kate Nesbitt, pp. 412-28. New York: Princeton Architectural Press, 1996.

Oakes, Timothy. "Ethnic Tourism in Rural Guizhou: Sense of Place and the Commerce of Authenticity." In Tourism, Ethnicity, and the State in Asian and Pacific Societies, ed. M. Picard and R. Wood, pp. 35-70. University of Hawai'i Press, 1997.

Oakes, Timothy. "Get Real! On Being Yourself and Being a Tourist." In Travels in Paradox: Remapping Tourism, ed. C. Minca and T. Oakes, pp. 229-50. Lanham: Rowman and Littlefield, 2006.

Oakes, Timothy. "Place and the Paradox of Modernity." Annals of the Association of American Geographers 87:3 (1997), pp. 509-31.

Petzet, Michael. "Genius Loci-The Spirit of Monuments and Sites." In Conserving the Authentic: Essays in Honour of Jukka Jokilehto, ed. Nicholas Stanley-Price and Joseph King, pp. 63-68. Rome: ICCROM International Centre for the Study of the Preservation and Restoration of Cultural Property, 2009.

Phillips, David. Exhibiting Authenticity. Manchester University Press, 1997.

Rickly-Boyd, Jillian M. "Authenticity \& Aura: A Benjaminian Approach to Tourism." Annals of Tourism Research 39:1 (2012), pp. 269-89.

Rickly-Boyd, Jillian M. "Existential Authenticity: Place Matters." Tourism Geographies: An International Journal of Tourism Space, Place and Environment 15:4 (2013), pp. 680-86.

Riegl, Alois. "The Modern Cult of Monuments: Its Character and Origin.” Oppositions 25 (Fall 1982), pp. 21-51.

Shils, Edward. Tradition. University of Chicago Press, 1981.
Summers, David. Real Spaces: World Art History and the Rise of Western Modernism. New York: Phaidon Press, 2003.

UNESCO World Heritage Committee. "Glossary of World Heritage Terms." In Glossary of World Heritage Terms, by UNESCO Convention Concerning the Protection of the World Cultural and Natural Heritage. 1996. Last modified December 1996. http://whc.unesco.org/archive/gloss96. htm.

UNESCO World Heritage Committee. "What Is Intangible Cultural Heritage?” UNESCO: Intangible Cultural Heritage. https://ich.unesco.org/en/ what-is-intangible-heritage-00o03.

Upton, Dell. “The Tradition of Change." Traditional Dwellings and Settlements Review 5:1 (Fall 1993), pp. 9-15.

Weiler, Katharina. "Aspects of Architectural Authenticity in Chinese Heritage Theme Parks." In Authenticity in Architectural Heritage Conservation: Discourses, Opinions, Experiences in Europe, South and East Asia, ed. Katharina Weiler and Niels Gutschow, pp. 219-46. Cham: Springer, 2017.

Zancheti, Sílvio, Flaviana Lira, and Rosane Piccolo. "Judging the Authenticity of the City." In Conserving the Authentic: Essays in Honour of Jukka Jokilehto, ed. Nicholas StanleyPrice and Joseph King, pp. 163-68. Rome: ICCROM, 2009.

Zhao, Yawei. “'China’s Leading Historical and Cultural City': Branding Dali City through Public-Private Partnerships in Bai Architecture Revitalization." Cities: The International Journal of Urban Policy and Planning 49 (2015), pp. 106-12.

Zhu, Yujie. "Authenticity and Heritage Conservation in China: Translation, Interpretation, Practices." In Authenticity in Architectural Heritage Conservation: Discourses, Opinions, Experiences in Europe, South and East Asia, ed. Katharina Weiler and Niels Gutschow, pp. 187-200. Cham: Springer, 2017.

Zhu, Yujie. "Cultural Effects of Authenticity: Contested Heritage Practices in China." International Journal of Heritage Studies 21:6 (2015), pp. 594-608.

Zhu, Yujie. "Performing Heritage: Rethinking Authenticity in Tourism." Annals of Tourism Research 39:3 (2012), pp. 1495-1513. 